\title{
Improvements of synergetic aerosol retrieval for ENVISAT
}

\author{
T. Holzer-Popp ${ }^{1}$, M. Schroedter-Homscheidt ${ }^{1}$, H. Breitkreuz ${ }^{2}$, D. Martynenko ${ }^{1}$, and L. Klüser ${ }^{1,3}$ \\ ${ }^{1}$ German Aerospace Center (DLR), German Remote Sensing Data Center (DFD), Oberpfaffenhofen, Germany \\ ${ }^{2}$ Julius-Maximilians-University of Würzburg, Department of Geography, Würzburg, Germany \\ ${ }^{3}$ University of Augsburg, Institute of Physics, Augsburg, Germany
}

Received: 3 January 2008 - Published in Atmos. Chem. Phys. Discuss.: 13 February 2008

Revised: 26 November 2008 - Accepted: 26 November 2008 - Published: 18 December 2008

\begin{abstract}
The synergetic aerosol retrieval method SYNAER (Holzer-Popp et al., 2002a) has been extended to the use of ENVISAT measurements. It exploits the complementary information of a radiometer and a spectrometer onboard one satellite platform to extract aerosol optical depth (AOD) and speciation (as a choice from a representative set of pre-defined mixtures of water-soluble, soot, mineral dust, and sea salt components). SYNAER consists of two retrieval steps. In the first step the radiometer is used for accurate cloud screening, and subsequently to quantify the aerosol optical depth (AOD) at $550 \mathrm{~nm}$ and spectral surface brightness through a dark field technique for different predefined aerosol mixtures. In the second step the spectrometer is applied to choose the most plausible aerosol mixture through a least square fit of the measured spectrum with simulated spectra using the mixture-dependent values of AOD and surface brightness retrieved in the first step. This method was developed and a first case study evaluation against few (15) multi-spectral ground-based AERONET sun photometer observations was conducted with a sensor pair (ATSR-2 and GOME) onboard ERS-2. Due to instrumental limitations the coverage of SYNAER/ERS-2 is very sparse. Therefore, SYNAER was transferred to similar sensors AATSR and SCIAMACHY onboard ENVISAT. While transferring to the new sensor pair significant improvements in the methodology were made based on a thorough evaluation of the methodology: (1) an update of the aerosol model, (2) improved cloud detection in the tropics and sub tropics, and (3) an enhanced dark field albedo characterization. This paper describes these improvements in detail and assesses their combined impact on the results. After a brief assessment of atmospheric noise impact on
\end{abstract}

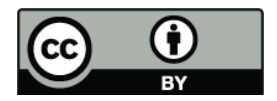

Correspondence to: T. Holzer-Popp (thomas.holzer-popp@dlr.de) comparisons of pixel and station measurements a validation against ground-based measurements establishes error bars for the SYNAER/ENVISAT method version 2.0. A theoretical analysis of the information content with regard to aerosol composition (second retrieval step) is presented to quantify the potential and limitations of this new capability provided by the SYNAER method. Building on this analysis, first seasonal and monthly composition results calculated by applying SYNAER version 2.0 to AATSR and SCIAMACHY are shown to demonstrate the potential of the approach. An intercomparison to earlier results of SYNAER version 1.0 is made for both the validation and the example datasets.

\section{Introduction}

Need for observations of atmospheric aerosol composition

Air pollution by solid and liquid particles suspended in the air, so-called aerosols, is one of the major concerns in many countries on the globe. One focus of concern is related to aerosols from anthropogenic origin mainly by combustion processes (industry, vehicle transport, heating, biomass burning). In developed countries improved combustion and filtering methods have led to a general decrease of particle concentrations in total suspended matter but new concern arises from potential health impact of increasing numbers of smaller aerosols, so-called nano-particles in particular from diesel engines (Pope et al., 2002). Stedman (2004) reports that $21-38 \%$ of total excess deaths in the UK during the summer heat wave of 2003 were attributable to elevated ozone and particle concentrations. On the other hand developing countries still suffer from high total particle loads in the air. Furthermore, natural aerosols (mainly dust and sea salt) also contribute significantly to background and episodically severely increased particle concentrations. Dust can also act

Published by Copernicus Publications on behalf of the European Geosciences Union. 
as carrier for long-range transport of diseases, e.g. from the Sahara to the Caribics or Western Europe (Pohl, 2003), or even once around the globe (Prospero et al., 2002), as Chinese yellow sand was detected as far as the Swiss Alps. Also well known in principle are direct (by reflecting light back to space) and several indirect (e.g. by acting as cloud condensation nuclei) climate effects of aerosols, although large uncertainties exist in the exact values of the forcing. Kaufman et al. (2002) point out, that the absorption behavior of particles (mainly soot and minerals) needs to be known to assess their total direct and indirect climate effects (strongly absorbing particles can regionally reverse the sign of the aerosol direct forcing from cooling to heating or suppress cloud formation). Finally, the highly variable atmospheric aerosol load has a major impact on satellite observations of the Earth's surface (thus requiring atmospheric correction of their blurring effect) and the solar irradiance which is exploited in solar energy applications (aerosols are the determining factor in clear-sky conditions).

In the light of this overall picture, climate monitoring, long-term air pollution monitoring as well as short term forecasting of pollution levels need to take into account intercontinental transport processes and the composition of the atmospheric particle load. Satellite observations of the total aerosol mass have experienced significant improvements in the last few years thanks to improved instrumentation and enhanced retrieval algorithms. Thus they offer the potential to regularly monitor the global aerosol distribution and by assimilating these measurements into chemistry-transportmodels to enhance particle forecasts especially for episodic severe pollution events, which are not covered by the underlying emission inventories. Furthermore, satellite data can contribute to deduce background and long-range transport patterns of aerosols.

This introduction is followed by a state of the art overview in Sect. 2. As the method presented in this paper focuses on characterizing the aerosol type, the summary of the state of the art in this section is restricted to recent developments which allow characterizing aerosol properties beyond aerosol optical depth. Section 3 gives an overview of the SYNAER principles and sensors (Sect. 3.1) and describes then the three major advances of the new SYNAER methodology version 2.0 during the transfer to ENVISAT. Section 3.2 deals with an extension of the aerosol component database to include higher values of the single scattering albedo for soot and mineral dust based on more recent ground-based observations; Sect. 3.3 presents two additions to the cloud screening which make sure that desert dust outbreaks over tropical and sub-tropical ocean are not masked out as clouds and that convective warm-top clouds are not missed. An improved dark field method, which takes into account the dependence of the correlation between mid-infrared and visible channels on the amount of vegetation is described in Sect. 3.4. Section 4 provides then the evaluation of the SYNAER/ENVISAT version 2.0 results. Based on all these changes, validation of SYNAER results at 440, 550 and $670 \mathrm{~nm}$ for 42 orbits in summer 2005 against AERONET measurements (Sect. 4.1) is made including an analysis of atmospheric noise effects on the validation results. Then, a first 4-month dataset derived with SYNAER version 2.0 from ENVISAT sensors AATSR and SCIAMACHY (Sect. 4.2) is presented. Furthermore, an analysis of the information content of the (additional) second retrieval step with regard to aerosol composition including realistic noise in the retrieval is made in Sect. 4.2. Both, validation and example datasets also contain an inter-comparison to results achieved with the older SYNAER/ENVISAT version 1.0. The paper concludes with a discussion and outlook in Sect. 5.

\section{State of the art overview with regard to retrieving aerosol type}

A comprehensive optical retrieval of the properties of the atmospheric aerosol load would comprise of spectral AOD (or AOD at $550 \mathrm{~nm}$ and the Angstrom coefficient) and single scattering absorption plus phase function together with relative AOD fractions of various size classes and of nonspherical particles. On the micro-physical level the respective information would translate into the number or mass densities, spectral complex refractive indices, size distributions and particle shapes of several components. As the atmospheric retrieval problem generally is an ill-posed problem with only few observables, many if not most of these parameters need to be estimated. And thus, the retrieval of additional aerosol properties beyond AOD is still in its infancy. Also the validation of such derived parameters is very complex due to lack of sufficient and appropriate data for intercomparison. This section provides an overview of methods to characterize additional aerosol properties. A good overview of different satellite retrieval principles to derive spatial-temporal patterns of aerosol optical depth (AOD) is presented in Kaufman et al. (1997).

A best fit between measured top-of-atmosphere and precalculated reflectances of the dual view Advanced Along Track Scanning Radiometer (AATSR) near-infrared and visible bands provides the Ångström coefficient and indications on composition, such as the dominant aerosol types that have been determined for a variety of aerosol mixtures (Veefkind et al., 1998; Robles-Gonzales et al., 2006). The aerosol types considered over Europe are marine and anthropogenic aerosols, which are externally mixed. Comparisons of the retrieved Ångström exponent against aircraft sun-photometer measurements have shown good agreement (Veefkind et al., 1999).

The Oxford RAL Aerosol and Cloud (ORAC) retrieval scheme (Marsh et al., 2004) has been applied to AATSR and Spinning Enhanced Visible and Infrared Imager (SEVIRI) data. The approach uses assumed aerosol optical properties based on the Optical Properties of Aerosols and 
Clouds database (OPAC, Hess et al., 1998). A fit to the observed top of atmosphere radiances is produced by varying the aerosol optical depth and effective radius, as well as the reflectance of the underlying surface.

The NASA-operated Multi-angle Imaging SpectroRadiometer (MISR) instrument on the Terra satellite provides a retrieval of one or more climatologic aerosol models, each of which is characterized as a mixture of up to three previously chosen pure particle components (Kahn et al., 2005). The climatologic models are defined by total aerosol optical depth and the percentage aerosol optical depths of the pure particle classes.

The MODerate resolution Imaging Spectro-radiometer (MODIS) instrument aboard NASA's Terra and Aqua satellites has been providing AOD data since the year 2000 for many applications in atmospheric, land-based and oceanic research. By summer 2007, a reprocessing campaign with improved versions of Level 1 science algorithms called Collection 5 (C005) has been completed for seven years of MODIS/Terra and five years of MODIS/Aqua data (Levy et al., 2007). A new parameter in MODIS Collection 5 is the AOD attributed to small particles, "fine AOD". It is calculated by multiplication of the total AOD with the fractional contribution of fine (small sized) aerosol in the total AOD. As in the case of the Ångström exponent, correlation with retrieved parameters against ground based measurements is still not satisfying, even after the algorithm changes of the Collection 5 reprocessing. This little improvement is partly due to the fact that MODIS still derives too much finedominated aerosol over land (Remer et al., 2005).

Another approach to improve the MODIS Collection 4 aerosol retrieval is the Deep Blue Algorithm, which adds the $412 \mathrm{~nm}$ channel to the channels at 470 and $670 \mathrm{~nm}$ to retrieve AOD and single scattering albedo. Reprocessing of five years of MODIS aerosol data of the Aqua platform with this algorithm has been completed simultaneously with the MODIS Collection 5 reprocessing effort. The Deep Blue approach is not very sensitive to the height of aerosol layers and can be applied for aerosol retrieval over different surfaces including bright desert areas (Hsu et al., 2004). Validation efforts for several sites and episodes have shown that level-2 AOD from the MODIS Deep Blue algorithm is generally within $25 \%$ of AOD measured by the sites of the AERONET network. Comparisons of retrieved Ångström exponent values with those computed from the direct sun measurements also show that this approach is able to separate small from coarse mode particles, even for very heterogeneously mixed aerosol environments (Hsu et al., 2006)

A technique to derive the aerosol mass load and particle number concentration from nadir scanning multi-spectral radiometers, like Medium Resolution Imaging Spectrometer (MERIS), is described in Kokhanovsky et al. (2006). Information on surface reflectivity is determined by a linear mixing model of spectra for vegetated and bare soil, following the Bremen Aerosol Retrieval (BAER) approach described by von Hoyningen-Huene et al. (2003). AOD is then retrieved for several channels at less than $670 \mathrm{~nm}$ of the measured spectrum of top-of-atmosphere reflectance, using precalculated radiative transfer values with fixed aerosol phase functions and single scattering albedo either from aerosol models, given by OPAC (Hess et al., 1998) or from experimental campaigns. This multi-spectral approach also allows for the determination of the Ångström exponent. A parameterization described in Kokhanovsky et al. (2006) is used to calculate effective particle radius and their columnar concentration from spectral AOD values, thus deriving information about ground particulate matter $\left(\mathrm{PM}_{10}\right)$ from space-borne retrievals of AOD. Despite common problems with ground truth due to the mismatch of point surface observations against space-averaging satellite retrievals, the aerosol characteristics derived within a case study are within reasonable values for atmospheric aerosol characteristics (Kokhanovsky et al., 2006).

The third POLDER (POLarization and Directionality of the Earth Reflectance) instrument onboard the PARASOL (Polarization and Anisotropy of Reflectances for Atmospheric Sciences coupled with Observations from a Lidar) platform matches aerosol polarization measurements against pre-calculated radiative transfer values for a set of aerosol models, leading to AOD values at various wavelengths as well as the Ångström exponent (Deuzé et al., 2001). PARASOL retrieval over land is mainly sensitive to small particles such as the aerosols created by anthropogenic pollution or biomass burning. Larger aerosol particles, like desert dust, do not polarize sunlight and therefore can not be retrieved quantitatively. This means that only the fine fraction contribution and not the total AOD can be derived. Validation studies over North-Eastern China have shown that there is a good general agreement between the AERONET fine-mode AOD and the PARASOL level 2 AOD, whereas the Ångström exponent seems to be overestimated (Fan et al., 2007).

Due to the differences in cloud screening and spatialtemporal sampling as well as the different underlying aerosol models the various aerosol datasets exhibit significant differences even in the basic parameter AOD (e.g. Myhre et al., 2005). The next logical step in aerosol retrieval relies on exploiting synergies of different instruments to advance the retrieval of a multi-parameter description of the atmospheric aerosol loading. This is the general aim of the NASA/CNES A-train aerosol satellite constellation consisting of MODIS, MISR, OMI, CALIPSO, PARASOL, each of which independently retrieves different aerosol properties. Another approach in this direction is the SYNAER (SYNergetic AErosol Retrieval) method which was developed to exploit a combination of a radiometer (ATSR-2, Along Track Scanning Radiometer 2) and a spectrometer (GOME, Global Ozone Monitoring Experiment) onboard one platform (ERS2, European Remote Sensing Satellite 2) to provide one multi-spectral retrieval ranging from deep blue to red bands with two different scales (Holzer-Popp et al., 2002a). A first 
case study validation and retrieval of 15 coincidences of these ERS-2 data with AERONET observations showed an AOD accuracy of 0.1 at 3 visible wavelengths (Holzer-Popp et al., 2002b).

\section{The retrieval method and its improvements}

\subsection{Overview of the SYNAER principles and sensors}

The synergetic aerosol retrieval method SYNAER delivers aerosol optical depth (AOD) and an estimation of the type of aerosols in the lower troposphere including a possible elevated dust layer (where in most cases the bulk of the aerosol loading is concentrated) over both land and ocean. In retrieving AOD the free tropospheric (AOD=0.03 free tropospheric above the boundary layer and a possible additional dust layer) and stratospheric ( $\mathrm{AOD}=0.01$ stratospheric background; valid since 1995 up to now) aerosol loading are kept constant at background conditions (World Climate Program, 1986), whereas only the boundary layer aerosol load and type and a possible additional elevated dust layer are varied. Further fine structures (multiple aerosol layers or layers disconnected from the ground) and periods of fresh volcanic activity in the stratosphere are not taken into account in SYNAER. The type of aerosol is estimated as percentage contribution of representative components from an extension of the OPAC (Optical Parameters of Aerosols and Clouds, Heß et al., 1998) dataset to AOD in the boundary layer. The high spatial resolution of the radiometer instrument permits accurate cloud detection with the APOLLO (AVHRR Processing Over cLouds, Land and Ocean) scheme, a combination of threshold and spatial variance tests (Kriebel et al., 1989 and 2003). The SYNAER aerosol retrieval algorithm comprises then of two major parts: (1) A dark field method exploiting single wavelength radiometer reflectances $(670 \mathrm{~nm}$ over land, $870 \mathrm{~nm}$ over ocean) and (2) a least square fit of visible top-of atmosphere reflectance spectra at 10 wavelengths $(415,428,460,485,500,516,523,554,615$, and $675 \mathrm{~nm})$ with the spectrometer. In the first step, AOD calculation over automatically selected and characterized dark pixels and surface albedo correction at 550,670, and $870 \mathrm{~nm}$ for a set of 40 different pre-defined boundary layer aerosol mixtures is done with the radiometer. In this first step AOD spatial interpolation to all $1 \mathrm{~km}^{2}$ radiometer pixels is conducted by triangulation, which allows then atmospheric correction with the same radiative transfer and atmospheric model to obtain surface reflectances for each cloud-free $1 \mathrm{~km}^{2}$ pixel at the 3 wavelengths of $550,670,870 \mathrm{~nm}$ and subsequently also to characterize the surface type. The first step is repeated for 40 different pre-defined aerosol mixtures. After spatial integration of these results $(40 \mathrm{AOD}, 40 \times 3$ surface reflectance values, 40 surface types) for the larger pixels of the spectrometer these parameters are used in the second step to simulate 40 spectra for the same set of 40 different aerosol mixtures using the same radiative transfer code. A least square fit of these calculated spectra to the measured spectrum delivers the correct AOD value (i.e. the AOD for the selected aerosol mixture) and - if a uniqueness test is passed - the plausible aerosol mixture. The entire method uses the same aerosol model of basic aerosol components, each of them representing optically similar aerosol species. These basic components are externally mixed into 40 different aerosol mixtures meant to cover a realistic range of atmospheric aerosol masses. For humidity dependent components two models with $50 \%$ and $80 \%$ relative humidity have been included. In the case of desert dust outbreaks, an elevated dust layer is added in the free troposphere. Also the underlying radiative transfer code is consistently used throughout all retrieval steps.

The "added value" in exploiting synergies of the two instruments is based on their complementary spectral and spatial information: The AOD retrieval over land uses radiometer measurements only from the $670 \mathrm{~nm}$ channel in order to avoid lower accuracy in characterizing surface reflectance at $550 \mathrm{~nm}$ and even more at $870 \mathrm{~nm}$, which are both affected by chlorophyll variability and therefore have weaker correlation with the $1.6 \mu \mathrm{m}$ band. From the spectrometer 10 wavelengths separated by tens of nanometers (though not all 10 wavelengths are linear independent in radiative transfer through the atmosphere) are used because this provides higher accuracy and higher information content (as will be shown in Sect. 4.2.1); of course, the draw back is in the large pixel size, but the gain is the capability to retrieve more than AOD and Angstrom coefficient. This is true as the 40 pre-defined aerosol mixtures have typically bi- (or even tri-) modal size distributions - to the knowledge of the authors mixing of basic components can not be retrieved with AATSR alone. This is the reason that the second instrument (the spectrometer) is used to estimate aerosol composition and thus not just the Angstrom coefficient (which assumes a mono-modal aerosol model and does also not characterize different absorption features). In addition, the different scales and spatial integration of the two instruments are sensitive to the choice of the aerosol mixture, because different single scattering albedo means different atmospheric effects for low and high surface reflectances due to the non-linear radiative transfer. Thus, also for spatially highly variable surface reflectance inside a spectrometer pixel the spatial integration leads to different results and thus different fit error (assuming a homogeneous aerosol load inside the entire spectrometer pixel). Only this last feature allows the differentiation between different absorption properties of aerosol components. However, a theoretical quantification of this effect appears very difficult.

There are two thresholds for brightness of the Earth's surface applied in the retrieval scheme: The first one (set to 0.085 at $670 \mathrm{~nm}$ ) applies to the first retrieval step for $1 \mathrm{~km}^{2}$ radiometer dark fields which are used for AOD retrieval. A second surface reflectance threshold (set at 0.20 at $670 \mathrm{~nm}$ 
during validation) is applied for the analysis of the results from the second retrieval step using the $60 \times 30 \mathrm{~km}^{2}$ spectrometer pixels, where based on knowing AOD and surface reflectance from the first retrieval step, a choice between simulated spectra for 40 aerosol mixtures is made. For the results of the second step a brighter threshold (as compared to step 1) is possible. The information content analysis in Sect. 4.2.1 shows with the example of bare soil, that this second step has less degrees of freedom for brighter surfaces, but is still applicable to some extent; only over extremely bright surfaces such as snow, there is no information content on aerosol composition at all (due to the higher noise level of bright surfaces). Evidently, the second retrieval step can only be conducted, if suitable dark pixels for the first retrieval step are available inside or near to the spectrometer pixel.

For clearer reference we name the original SYNAER version 1.0 (developed for ERS-2, but also applied to ENVISAT). The very weak sampling of the combination of the two sensors onboard ERS-2 (only 3 days with $120 \mathrm{~km}$ overlapping swath width and small scan pixels of $80 \times 40 \mathrm{~km}^{2}$ in each month) provided serious limitations for a systematic validation and application. This method has therefore been transferred to a new sensor combination onboard ENVISAT together with a thorough assessment and improvement of individual retrieval steps using a significantly larger dataset.

SYNAER / ENVISAT exploits the combination of the radiometer AATSR and the spectrometer SCIAMACHY. The Advanced Along Track Scanning Radiometer (AATSR) and the Scanning Imaging Absorption Spectrometer for Atmospheric Cartography (SCIAMACHY) are active onboard the European Environmental Satellite ENVISAT since March 2002 and simultaneously observe the same area on the globe. AATSR measures Earth reflected radiances in 5 spectral bands centered at $0.55,0.67,0.87,1.6,3.7 \mu \mathrm{m}$ (with some additional thermal signal at $3.7 \mu \mathrm{m}$ ) with bandwidths of 25 to $66 \mathrm{~nm}$ and brightness temperatures in 2 thermal channels at 11 and $12 \mu \mathrm{m}$. All observations are taken under two viewing angels (nadir and $55^{\circ}$ forward) with a ground resolution of approximately $1.1 \mathrm{~km}^{2}$ at nadir. The main target of AATSR is the observation of sea surface temperature with high accuracy. SCIAMACHY observes near-nadir and limb reflection from the Earth in the range from 240 to $790 \mathrm{~nm}$ with a spectral resolution of $0.2 \mathrm{~nm}$ to $0.4 \mathrm{~nm}$ and in selected bands between 800 and $2400 \mathrm{~nm}$ with a resolution of few $\mathrm{nm}$ and a pixel size of $60 \times 30 \mathrm{~km}^{2}$ in nadir view. Its principal goal is the monitoring of stratospheric ozone but further stratospheric and tropospheric trace gases can be also measured. Because both instruments measure the solar illumination regularly, earth reflectances can be calculated with significantly reduced calibration errors as compared to the use of calibrated radiances. In the latest calibration version the cross-correlation of spectrally and spatially integrated reflectances measured by both instruments (and against another radiometer MERIS onboard ENVISAT) was found to satisfy high accuracy requirements with deviations on the or- der of $1 \%$. To assure consistent retrieval (also for the earlier SCIAMACHY product version 5.4 with significantly larger absolute calibration errors) the SCIAMACHY absolute reflectance values are corrected against the coincident AATSR values for each pixel. In this paper no use is made of dark fields which are selected with the $3.8 \mu \mathrm{m}$ channel (as in version 1.0) as their inclusion provides no additional coverage whereas their albedo estimation seems more inaccurate due to the thermal signal contribution. Also the variance test of version 1.0 for each entire $512 \times 512 \mathrm{~km}^{2}$ frame, which was needed for the ERS-2 data due to the small GOME pixel number, has no longer been applied. Finally, the different retrieval scheme over ocean, which has some impact on coastal zone validation stations, has not been further investigated in this paper. All other parts of the methodology as described in Holzer-Popp et al. (2002a) are not changed and therefore not described here in further detail. A first thorough assessment of SYNAER version 1.0 applied to EVNISAT data led to three major improvements, which are described in the rest of this section. The upgraded SYNAER method including these three improvements is denoted as SYNAER version 2.0 (and so far only applied to ENVISAT data).

\subsection{Extension of the aerosol model}

As described in Holzer-Popp et al. (2002a) basic aerosol components, their optical features and log-normal size distribution are taken from the OPAC database (Hess et al., 1998). Table 1 summarizes their relevant microphysical properties and optical characteristics derived from Mie calculations. However, on the basis of more recent campaigns and AERONET data exploitations some specific items have been updated against SYNAER version 1.0.

The original soot component was split in two components for strongly absorbing diesel soot (DISO) more representative for industrial areas and weakly absorbing biomass burning soot (BISO). The optical properties of strongly absorbing diesel soot were taken from Schnaiter et al. (2003), while optical properties for soot from biomass burning cases as e.g. in Amazonian, South American cerrado, African savannah and boreal regions were adopted from Dubovik et al. (2002). As size distributions measured in Schnaiter et al. (2003) were similar to the OPAC database, the size distribution described in the OPAC database are used also for the DISO and BISO components replacing now the original OPAC SOOT component.

For mineral dust a new, additional component (MILO, mineral dust with low absorption) was introduced in order to take dust sources with lower hematite content into account. Moulin et al. (2001) discuss that earlier measurements (Patterson et al., 1997, used e.g. in OPAC) were conducted in regions with large hematite content. As hematite is a strongly absorbing material, already small amounts can change the optical properties of atmospheric dust significantly. Recent measurements as e.g. Schnaiter et al., 2003; Moulin et al., 
Table 1. Optical characteristics of basic components used for external mixing in SYNAER. (New components are highlighted).

\begin{tabular}{|c|c|c|c|c|c|c|c|c|}
\hline Component & Species & $\begin{array}{l}\text { Complex } \\
\text { refract. Index } \\
\text { at } 550 \mathrm{~nm}\end{array}$ & $\begin{array}{l}\text { Mode radius } \\
{[\quad[\mu \mathrm{m}]}\end{array}$ & $\begin{array}{l}\text { Stand. Dev. of } \\
\text { size distribution }\end{array}$ & $\begin{array}{l}\text { Particle density } \\
\qquad\left[\mathrm{g} / \mathrm{cm}^{3}\right]\end{array}$ & $\begin{array}{l}\text { Extinction coefficient } \\
\text { for } 1 \text { particle per } \mathrm{cm}^{3} \\
\text { at } 550 \mathrm{~nm}\left[\mathrm{~km}^{-1}\right]\end{array}$ & $\begin{array}{l}\text { Single scattering } \\
\text { albedo at } 550 \mathrm{~nm}\end{array}$ & $\begin{array}{l}\text { Literature } \\
\text { source }\end{array}$ \\
\hline $\begin{array}{l}\text { WASO, } \\
\text { RH }=70 \%\end{array}$ & $\begin{array}{l}\text { Sulfate/ } \\
\text { nitrate }\end{array}$ & $1.53-0.0055 \mathrm{i}$ & 0.028 & 2.24 & 1.33 & 7.9 e- 6 & 0.981 & Hess et al., 1998 \\
\hline INSO & $\begin{array}{l}\text { Mineral dust, } \\
\text { high hematite } \\
\text { content }\end{array}$ & $1.53-0.008 \mathrm{i}$ & 0.471 & 2.51 & 2.0 & 8.5 e- 3 & 0.73 & Hess et al., 1998 \\
\hline INSL & $\begin{array}{l}\text { Mineral dust, } \\
\text { low hematite } \\
\text { content }\end{array}$ & $1.53-0.0019 i$ & 0.471 & 2.51 & 2.0 & $8.5 e-3$ & 0.891 & Dubovik et al., 2002 \\
\hline $\begin{array}{l}\text { SSAM, } \\
\mathrm{RH}=70 \%\end{array}$ & $\begin{array}{l}\text { Sea salt, } \\
\text { accumulation } \\
\text { mode }\end{array}$ & $1.49-0 \mathrm{i}$ & 0.378 & 2.03 & 1.2 & $3.14 \mathrm{e}-3$ & 1.0 & Hess et al., 1998 \\
\hline $\begin{array}{l}\text { SSCM, } \\
\mathrm{RH}=70 \%\end{array}$ & $\begin{array}{l}\text { Sea salt, } \\
\text { coarse } \\
\text { mode }\end{array}$ & $1.49-0 \mathrm{i}$ & 3.17 & 2.03 & 1.2 & $1.8 \mathrm{e}-1$ & 1.0 & Hess et al., 1998 \\
\hline BISO & $\begin{array}{l}\text { Biomass } \\
\text { burning } \\
\text { soot }\end{array}$ & $1.63-0.036 i$ & 0.0118 & 2.0 & 1.0 & $1.5 e-7$ & 0.698 & Dubovik et al., 2002 \\
\hline DISO & $\begin{array}{l}\text { Diesel } \\
\text { soot }\end{array}$ & $1.49-0.67 i$ & 0.0118 & 2.0 & 1.0 & $7.8 e-7$ & 0.125 & Schnaiter et al., 2003 \\
\hline MITR & $\begin{array}{l}\text { Transported } \\
\text { minerals, high } \\
\text { hematite content }\end{array}$ & $1.53-0.0055 \mathrm{i}$ & 0.5 & 2.2 & 2.6 & $5.86 \mathrm{e}-3$ & 0.837 & Hess et al., 1998 \\
\hline MILO & $\begin{array}{l}\text { Transported } \\
\text { minerals, low } \\
\text { hematite content }\end{array}$ & $1.53-0.0019 i$ & 0.5 & 2.2 & 2.6 & $5.86 e-3$ & 0.93 & Dubovik et al., 2002 \\
\hline
\end{tabular}

2001; Sinyuk, et al., 2003 in Bahrain, Cape Verde, Sahara and Saudi Arabia regions with low hematite content show a reduced imaginary part of the refractive index between 0.001 and 0.002 compared to the OPAC value of 0.0055 . Larger hematite concentrations can be found only in restricted areas as the Sahel area, Northern India and Eastern Australia (Claquin et al., 1999). Also, measurements from the GOES8 satellite optimally reproduce ground measurements of mineral dust concentrations if an imaginary part of 0.0015 is assumed (Wang et al., 2003).

As the insoluble component in OPAC (INSO) is modeled with the identical refractive index as the mineral transported component MITR, also an insoluble component with low absorption (INSL) was introduced. Both, MILO and INSL have the same size distributions as the OPAC components MITR and INSO, respectively. Table 1 includes also the microphysical characteristics of these additional basic components.

Table 2 shows the updated definition of the 40 mixtures used in the SYNAER 2.0 retrieval method using the extended set of basic components. The set of 40 mixtures is meant to model all principally existing aerosol types and to allow for some variability in the composition of each type. This set of mixtures has proven to provide a fit in the GOME spectra retrieval which is in many cases at a $1 \%$ noise level. Values in the table show the vertical profile, relative humidity in the boundary layer and the percentage contribution to the optical depth at $550 \mathrm{~nm}$ of the respective components. In the case of a desert dust outbreak of transported minerals, the lowest aerosol layer of $4-6 \mathrm{~km}$ is modeled as two distinct sub-layers representing a dust layer above background aerosols, as they occur in nature. Two groups of 20 mixtures, each are applied where either relative humidity or the absorption of the mineral component is altered. Alternative values are marked with grey boxes: For example, mixture number 1 has $50 \%$ relative humidity and mixture number 21 has $80 \%$ relative humidity; mixture number 2 has a $5 \%$ insoluble (large absorption) component, whereas mixture number 22 has a $5 \%$ insoluble (low absorption) contribution to the optical thickness at $550 \mathrm{~nm}$.

\subsection{Improved cloud screening}

Cloud Screening in SYNAER is achieved through adaptation of the Advanced Very High Resolution Radiometer (AVHRR) Processing scheme Over cLouds, Land and Ocean (APOLLO), described in Saunders and Kriebel (1988), Kriebel et al. $(1989,2003)$ to AATSR. Unfortunately, this cloud screening scheme adaptation to AATSR has two shortcomings, which have to be accounted for in order to derive an accurate cloud mask for aerosol retrievals in all climate zones including the sub-tropics.

First, heavy aerosol load over oceans (mainly mineral dust, to minor parts smoke plumes from wildfires) is classified as "cloudy" by APOLLO and these AATSR pixels are then not used for the retrieval of AOD in SYNAER, leading to somewhat too small AOD values in the dust belts. The second shortcoming is an improper detection of shallow cumulus cloud cover over land due to a simple temperature threshold test for the rejection of cloudy pixels in order to 
Table 2. Pre-defined external aerosol mixtures of the basic components detailed in Table 1 which are used in SYNAER.

\begin{tabular}{|c|c|c|c|c|c|c|c|c|c|c|c|c|c|}
\hline & & & & & \multicolumn{9}{|c|}{ Component contributions to AOD550 [\%] } \\
\hline \multicolumn{2}{|c|}{ No. } & Name & $\begin{array}{l}\mathrm{RH} \\
{[\%]}\end{array}$ & $\begin{array}{c}\text { Vert.prof. } \\
{[\mathrm{km}]}\end{array}$ & WASO & INSO & INSL & SSAM & SSCM & BISO & DISO & MITR & MILO \\
\hline 1 & 21 & $\begin{array}{l}\text { Pure } \\
\text { water-soluble }\end{array}$ & $50 / 80$ & 2 & 100 & & & & & & & & \\
\hline 2 & 22 & & & & 95 & 5 & 5 & & & & & & \\
\hline 3 & 23 & Continental & 50 & 2 & 90 & 10 & 10 & & & & & & \\
\hline 4 & 24 & & & & 85 & 15 & 15 & & & & & & \\
\hline 5 & 25 & & & & 30 & & & 70 & & & & & \\
\hline 6 & 26 & Maritime & $50 / 80$ & 2 & 30 & & & 65 & 5 & & & & \\
\hline 7 & 27 & & & & 15 & & & 85 & & & & & \\
\hline 8 & 28 & & & & 15 & & & 75 & 10 & & & & \\
\hline 9 & 29 & Polluted & $50 / 80$ & 2 & 90 & & & & & & 10 & & \\
\hline 10 & 30 & watersoluble & & & 80 & & & & & & 20 & & \\
\hline 11 & 31 & Polluted & 50 & 2 & 80 & 10 & 10 & & & & 10 & & \\
\hline 12 & 32 & Continental & & & 70 & 10 & 10 & & & & 20 & & \\
\hline 13 & 33 & Polluted & $50 / 80$ & 2 & 40 & & & 45 & 5 & & 10 & & \\
\hline 14 & 34 & Maritime & & & 30 & & & 40 & 10 & & 20 & & \\
\hline 15 & 35 & Desert & & $2-4$ & 25 & & & & & & & 75 & 75 \\
\hline 16 & 36 & Outbreak & 50 & $3-5$ & 25 & & & & & & & 75 & 75 \\
\hline 17 & 37 & & & $4-6$ & 25 & & & & & & & 75 & 75 \\
\hline 18 & 38 & Biomass & & & 85 & & & & & 15 & & & \\
\hline 19 & 39 & Burning & $50 / 80$ & 3 & 70 & & & & & 30 & & & \\
\hline 20 & 40 & & & & 55 & & & & & 45 & & & \\
\hline
\end{tabular}

WASO $=$ water-soluble, INSO = insoluble, $\mathrm{INSL}=$ insoluble/low hematite, $\mathrm{SSAM}=$ sea salt accumulation mode, $\mathrm{SSCM}=$ sea salt coarse mode, $\mathrm{BISO}=$ biomass burning soot, DISO = diesel soot, MITR = mineral transported, MILO = mineral transported/low hematite; Mixture number $N$ and mixture number $N+20$ : alternative humidity or mineral composition, respectively.

not classify desert surfaces as low clouds. Thus, in some obviously cloudy AATSR scenes no clouds are detected, and those much too bright pixels are used for the AOD derivation, leading to biased AOD over land. Both shortcomings of the APOLLO cloud detection scheme require corrections to the cloud screening procedure, which are described below.

\subsubsection{Mineral dust over ocean}

APOLLO was developed to detect clouds from AVHRR data (Saunders and Kriebel, 1988) and not for remote sensing of atmospheric aerosols. Thus, in cases of heavy aerosol loads from North Africa getting transported across the Atlantic Ocean, the dust plumes are misclassified as "cloudy" by APOLLO due to their high shortwave-reflectance. With these heavy aerosol loads not being included in the SYNAER analysis, the resulting AOD in the dust plume area is surely underestimated. This exclusion of heavy dust plumes from the SYNAER process can be accounted for as follows.
Heavy dust plumes in the Atlantic region are usually embedded in an air layer often called Saharan Air Layer (SAL), which is described in detail e.g. by Wong and Dessler (2005). The main characteristic properties of this SAL are being warm, dry and well mixed. Thus $11 \mu \mathrm{m}$ brightness temperatures of dust-laden pixels are well above $273 \mathrm{~K}$. So this brightness temperature value is chosen as a first threshold, which prevents cool mixed-phase or ice clouds from being taken into account for the further analysis, together with scenes in polar regions. This condition can also be met by thin cirrus or semi-transparent clouds, so another criterion for the following dust discrimination scheme is the cloud type "low cloud" determined by the original APOLLO tests.

Dunion and Velden (2004) use images of the Geostationary Operational Environmental Satellites (GOES) to track the SAL across the Atlantic Ocean. They discriminate the "SALstrength" by means of the brightness temperature difference (BTD) between $11 \mu \mathrm{m}$ and $12 \mu \mathrm{m}$, arguing that non-SAL BTD values are well above $+5 \mathrm{~K}$. The SAL-strength analysed 
by Dunion and Velden (2004) does not directly represent the aerosol load or optical depth and also is sensitive to cloud screening.

The BTD alone does not seem to be an appropriate measure to discriminate miss-classified clouds (not shown), but it is a good method to select AATSR pixels which have to undergo further inspection. In this APOLLO improvement scheme a slightly more conservative BTD threshold of $+2 \mathrm{~K}$ is used, because heavy aerosol plumes can be shown to inhibit values well below this threshold (and low aerosol loads seem not to be miss-classified by APOLLO). Evan at al. (2006) use different BTD thresholds in different stadiums of their dust detection algorithm with the minimal threshold being $-0.5 \mathrm{~K}$ and the maximum BTD value, for which dust classification remains possible, being $+3.5 \mathrm{~K}$. For the purpose of saving computing time a single BTD threshold of $+2 \mathrm{~K}$ has been chosen here for the initial test.

Furthermore two reflectance thresholds are applied to preselect possible misclassified dust pixels: pixels have to have a $1.6 \mu \mathrm{m}$ reflectance value below 0.2 and a $0.6 \mu \mathrm{m}$ reflectance value below 0.3 . Brighter pixels classified as cloudy by APOLLO remain unchanged.

Thus the pre-selection scheme of possible miss-classified dust pixels consists of the following tests:

$T_{11 \mu \mathrm{m}}>273 \mathrm{~K} \wedge R_{1.6 \mu \mathrm{m}}<0.2 \wedge$
$R_{0.6 \mu \mathrm{m}}<0.3 \wedge T_{11 \mu \mathrm{m}}-T_{12 \mu \mathrm{m}} \leq 2 \mathrm{~K}$

Pixels classified as low-cloud covered by APOLLO, for which these tests apply, can still be cloud contaminated or aerosol loaded. The discrimination between clouds and mineral dust can be achieved by means of the ratio of reflectances at $1.6 \mu \mathrm{m}$ and $0.6 \mu \mathrm{m}$ due to the higher reflectance of water clouds at $1.6 \mu \mathrm{m}$ compared to mineral dust.

Figure 1 shows AATSR reflectance values at $1.6 \mu \mathrm{m}$ and at $0.6 \mu \mathrm{m}$ for a desert dust outbreak scene of 9 March 2006 off the Western coast of North Africa. The analysis includes a box area of $1000 \times 512$ AATSR pixels. For $0.6 \mu \mathrm{m}$ reflectances larger than about 0.1 one can clearly distinguish two different regimes in the scatter-plot. The lower branch, coloured in blue in the figure, represents pixels which can be identified as dust loaded by visual inspection (not shown). The upper branch, coloured in red, can be identified as definitely cloud covered in RGB images of the scene.

The discrimination between both branches does not exactly follow the reflectance ratio of 1 . Dust discrimination requires the condition

$$
\frac{R_{1.6 \mu \mathrm{m}}+0.035}{R_{0.6 \mu \mathrm{m}}}<1
$$

to be met. The additional constant, being 0.035 for AATSR, originates from a best fit test and can be shown to differ slightly for other sensors than AATSR (e.g. it is 0.03 for SEVIRI onboard the MSG satellite).

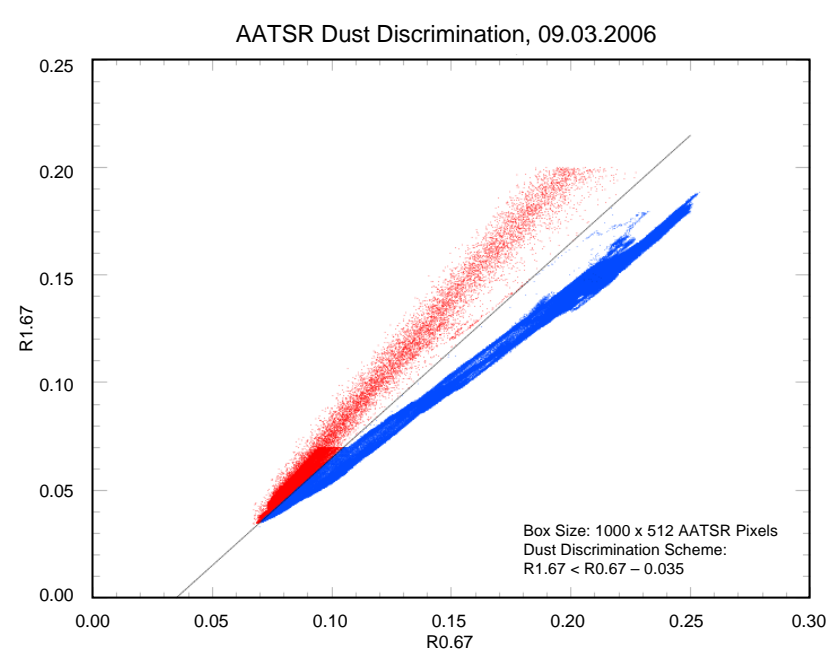

Fig. 1. Scatter plot of AATSR reflectances at $1.6 \mu \mathrm{m}$ against $0.6 \mu \mathrm{m}$ for a scene from 9 March 2006 showing the differentiation of heavy dust load and shallow stratocumulus clouds.

Furthermore, Fig. 1 shows that a discrimination between dust and cloud by means of the reflectance ratio is not possible for $0.6 \mu \mathrm{m}$ reflectances below about 0.1 , values corresponding to moderate to low dust load or thin low level clouds. For pixels, which meet the conditions listed in Eq. (2) and inhibit a $0.6 \mu \mathrm{m}$ reflectance below 0.1 , an even more conservative BTD threshold of $0 \mathrm{~K}$ is applied to discriminate misclassified pixels, as described in Huang et al. (2006) and also in Evan et al. (2006), while the reflectance ratio test is not applied for those pixels.

\subsubsection{Shallow convection over land}

Adapted to AATSR data, the APOLLO cloud detection scheme shows significant shortcomings in the detection of fields of shallow convective clouds over land, which can easily be classified as being "cloudy" by visual inspection of RGB images. This miss-classification of obviously cloudy pixels leads to a retrieval of high AOD for those AATSR pixels, resulting in a biased SYNAER AOD over land.

The original adaptation of APOLLO to AATSR data includes a temperature threshold test scheme for the exclusion of very bright desert surfaces from cloud detection. In this scheme, cloudy pixels having $11 \mu \mathrm{m}$ brightness temperatures above a scene-dependent threshold between $285 \mathrm{~K}$ and $305 \mathrm{~K}$ are rejected (from cloud detection) if they inhibit a $0.6 \mu \mathrm{m}$ reflectance below 0.6 . This test is included in the APOLLO scheme to determine whether a pixel is cloudy or above bright desert surface. Without this test, APOLLO classifies many desert areas as "cloudy" due to their high shortwave reflectance. On the other hand, inclusion of this test rejects pixels, which obviously show low level convective cloud fields with warm cloud top temperatures somewhere in the temperature range of the thresholds. This makes the 
application of a further test over land necessary, which accounts for these cloud fields and flags them "cloudy".

Only pixels classified as "cloud-free" by APOLLO after the temperature rejection tests within the APOLLO scheme are regarded for the additional tests described below. Furthermore the pixels have to have $11 \mu \mathrm{m}$ brightness temperatures in the range $285 \mathrm{~K}-305 \mathrm{~K}$, which covers the range of possible thresholds for the temperature rejection test. Pixels having $11 \mu \mathrm{m}$ brightness temperatures above the highest possible threshold value of $305 \mathrm{~K}$ remain flagged cloud-free, following the original APOLLO strategy for desert surfaces.

As a second test, the ratio of reflectances at $1.6 \mu \mathrm{m}$ and at $0.8 \mu \mathrm{m}$ has to be above 0.65 and below 1.0. This somewhat arbitrary threshold accounts for the near-equality of those reflectances for dense water clouds and desert surfaces which often have reflectance ratios well above 1.0 (not shown).

As only those conditions described so far are not enough to distinguish between desert surface and low cloud fields, pixels meeting the above conditions are re-classified as "cloudy", if either the conditions

$R_{0.8 \mu \mathrm{m}}>0.25 \wedge R_{0.6 \mu \mathrm{m}}>0.25 \wedge T_{11 \mu \mathrm{m}}-T_{12 \mu \mathrm{m}} \geq 1.25 \mathrm{~K}$

are met or if

$R_{0.8 \mu \mathrm{m}}>0.4 \wedge R_{0.6 \mu \mathrm{m}}>0.4 \wedge-0.5<T_{11 \mu \mathrm{m}}-T_{12 \mu \mathrm{m}}<1.25 \mathrm{~K}$

is true.

The threshold of 0.4 for the $0.6 \mu \mathrm{m}$ and the $0.8 \mu \mathrm{m}$ reflectances is adapted from Rosenfeld and Lensky (1998) for pixels with BTD lower than 1.25. This BTD test split value of $1.25 \mathrm{~K}$ results from the APOLLO algorithm. So, for BTD values larger than 1.25 a slightly lower reflectance threshold of 0.25 can be chosen, which follows the cloud detection method of Kaufman and Fraser (1997). Actually, those authors use a threshold of 0.2 for the $0.6 \mu \mathrm{m}$ reflectance, combined with a difference in brightness temperatures between $3.7 \mu \mathrm{m}$ and $11 \mu \mathrm{m}$ of larger than $+8 \mathrm{~K}$. A slightly higher threshold has been chosen here because in opposition to Kaufman and Fraser (1997) pixels having $11 \mu \mathrm{m}$ brightness temperatures warmer than $290 \mathrm{~K}$ are also included and no brightness temperature difference between the $3.7 \mu \mathrm{m}$ and the $11 \mu \mathrm{m}$ channel is used. Only the combination of both additional tests enables a proper discrimination between rejected desert surfaces and low cloud fields within the APOLLO cloud detection scheme.

Figure 2 shows an AATSR scene with a large number of obviously misclassified cloudy pixels. The left hand side of the image shows an RGB composite image, in which the lowlevel cloud field easily can be detected. On the right hand side the APOLLO cloud mask is shown. Green pixels show cloud free land and white pixels show clouds detected by the original APOLLO scheme. A clear disagreement between the cloud detection and the clouds seen in the composite occurs. The red pixels show pixels classified as cloud-covered by the improved APOLLO scheme, while not by the original

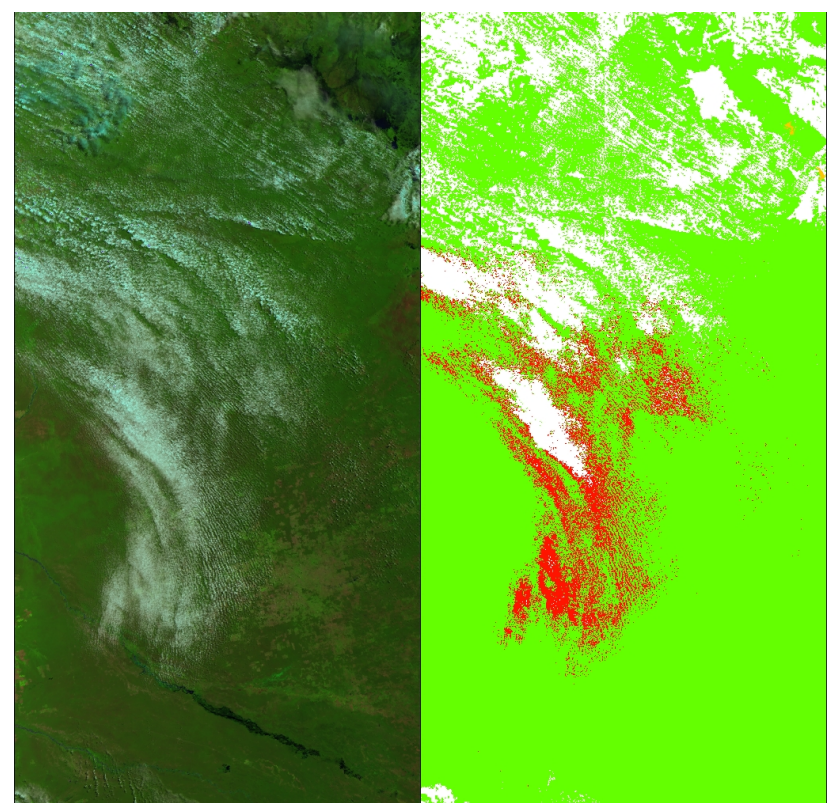

Fig. 2. AATSR scene over land on 8 March 2006 showing APOLLO miss-classifications. Green pixels are cloud-free land, white pixels are clouds detected by the original APOLLO scheme and red pixels show clouds only detected by the additional cloud detection scheme.

one. A great improvement of cloud detection is obvious and clearly shows its necessity.

The improved APOLLO cloud classification, extended by the tests described above, has been tested by visual inspection with 39 different AATSR orbits of the years 2006 and 2007 during all seasons with many scenes including low level convection and heavy dust plumes. These tests show clear improvements of the APOLLO cloud screening for SYNAER, which should clearly lead to a reduced bias in AOD both over land and over ocean.

It should be noted, that there can still be some very warm or moderately bright low level clouds which remain undetected by the improved APOLLO cloud screening procedure. On the other hand also slightly more desert pixels, showing no clear evidence of being cloudy, are flagged cloud covered with the improved scheme, leading to slightly too high mean cloud cover in desert regions. However, compared to the benefits of additional detection of low level clouds this miss-classification of potentially cloud free desert pixels can surely be accepted in the case of SYNAER.

\subsection{Improved dark field method}

As a thumb rule one can recall that in order to retrieve AOD with an accuracy of 0.1 the surface albedo of the treated dark field should be known with an accuracy of 0.01 (see e.g. Holzer-Popp et al., 2002a). To achieve this accuracy in an automatic retrieval procedure over land for AATSR (over ocean 

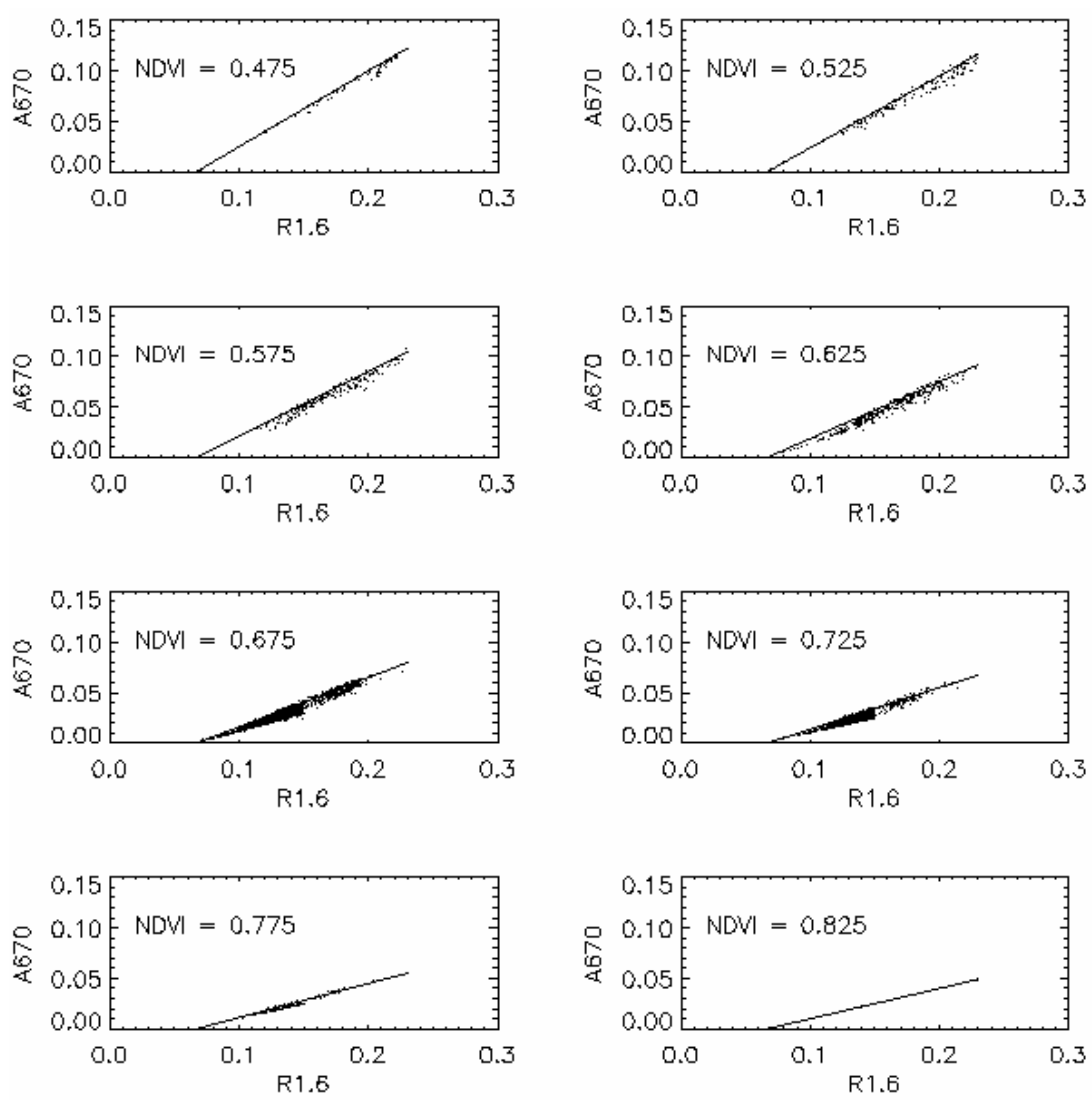

Fig. 3. Correlation between reflectances at $1.6 \mu \mathrm{m}$ and at $670 \mathrm{~nm}$ for suitable dark fields varying with normalized vegetation index NDVI. Vegetation surfaces with NDVI $>0.45$ and $R_{1.6}<0.23$ were chosen and are plotted for NDVI interwalls of 0.05 . The figure shows results based on 2474 automatically selected dark fields from 42 ENVISAT orbits in 2005 with AOD $<0.1$ and scattering angles between $140^{\circ}$ and $160^{\circ}$. Regression lines in each plot show the dependence function which is used in the SYNAER retrieval.

a different scheme is used, which is described in Holzer-Popp et al., 2002a), dark fields are selected from a combination of thresholds for the normalized vegetation index NDVI and the reflectance $R_{1.6}$ in the mid-infrared at $1670 \mathrm{~nm}$. Best values set in the retrieval are now NDVI $>0.5$ and $R_{1.6}<0.23$. For these dark field pixels the surface reflectance over land at $670 \mathrm{~nm}$ is then estimated by a linear regression with the reflectance at $1.6 \mu \mathrm{m}$ (since this mid-infrared reflectance is almost not affected by aerosols, except for large desert dust outbreaks). Similar to the latest update of the MODIS retrieval algorithm Collection 5 (regression between $2.2 \mu \mathrm{m}$ and 670/490 nm becomes vegetation dependant in Collection 5; Levy et al., 2007) this regression showed to depend on the vegetation amount. Figure 3 shows the regression of surface reflectance at $670 \mathrm{~nm}$ versus top of atmosphere reflectance at $1.6 \mu \mathrm{m}$ for intervalls of 0.05 in NDVI. For this plot 2474 dark fields were analyzed, where an AERONET sun photometer measurement was available within $60 \mathrm{~min}$ and $50 \mathrm{~km}$ from the respective AATSR pixel, where the AOD at $550 \mathrm{~nm}$ was below 0.1 and where the scattering angle was between $140^{\circ}$ and $160^{\circ}$. The surface reflectance was derived by atmospheric correction with the SYNAER radiative transfer algorithm and the respective AERONET AOD value. This analysis leads then to following regression function between top of atmosphere reflectances $R_{1.6}$ at $1.6 \mu \mathrm{m}$ and surface reflectances $R_{670}$ at $670 \mathrm{~nm}$ :

$R_{670}=a \cdot R_{1.6}+b+c$

with

$$
\begin{aligned}
& a=-1.5 \cdot \mathrm{NDVI}+1.5 \\
& b=0.1 \cdot \mathrm{NDVI}-0.1 \\
& c=0.05 \cdot\left(\cos \psi-\cos 150^{\circ}\right),
\end{aligned}
$$

where $\psi$ is the scattering angle. The third term is not shown in Fig. 3 as the few extreme values of the scattering angle were not included into this analysis, but it was found necessary to improve the AOD retrieval for a small number of cases with scattering angles close to $120^{\circ}$. Finally, dark fields where the estimated surface reflectance at $670 \mathrm{~nm}$ exceeds 0.085 are not used in the retrieval. 
In support of this regression function extracted by optimizing AOD agreement with nearby AERONET observations, Fig. 4 shows the results of applying the regression function to dark fields with all AOD values. This histogram of retrieved AOD errors against AERONET ground-based measurements (up to $50 \mathrm{~km}$ away) for the real dark field pixels confirms the NDVI and scattering angle dependant regression function. The achieved standard deviation (0.089) and bias (0.017) are quite satisfactory given the spatial and temporal differences to the AERONET station of up to $50 \mathrm{~km}$ and $60 \mathrm{~min}$.

This new regression function is used to determine the surface reflectance in the visible as main pre-condition for retrieving aerosol optical depth. In the ERS-2 SYNAER methodology a constant regression function $R_{670}=0.27$ ${ }^{*} R_{1.6}+0$. was used, which is obviously not satisfactory for global application. One drawback of using a regression based on NDVI is the fact, that the NDVI values themselves depend on the aerosol optical depth and are typically decreasing with increasing AOD. To overcome this dependence, a one-step iteration is conducted, where the preliminary retrieved AOD value is used to adjust the NDVI value and subsequently the same regression function is applied again to calculate a corrected visible surface reflectance, which is then exploited for a corrected AOD retrieval. The function derived empirically to provide optimal agreement of retrieved AOD after iteration against AERONET observations is:

$\mathrm{NDVI}_{\text {corrected }}=\mathrm{NDVI}+0.25 \cdot \mathrm{AOD}_{\text {preliminary }} / \mu_{0}$,

where $\mu_{0}$ is the cosine of the solar zenith angle.

\section{Evaluation of the improved methodology}

\subsection{Validation}

\subsubsection{Limitations of ground-based validation due to atmospheric noise}

Ground based photometer measurements are widely used to determine the accuracy of AOD satellite retrievals. However, if aerosol spatial-temporal high variability is not considered in validating satellite pixel (i.e. area averaged) results with station measurements (i.e. spot values), a missinterpretation can be done that the high RMSE values are solely due to the inaccuracies of the satellite retrieval method and its assumptions. Before summarizing the validation results against AERONET ground based photometer measurements therefore a quantitative estimate of the lowest RMSE possible when comparing the large SCIAMACHY pixel results to AERONET stations is provided. A possible method for quantifying the natural spatial variability of any given parameter are variogram analyses: they express the variability of a quantity, e.g. AOD, as measured at different locations but approximately at the same time, seen as a function

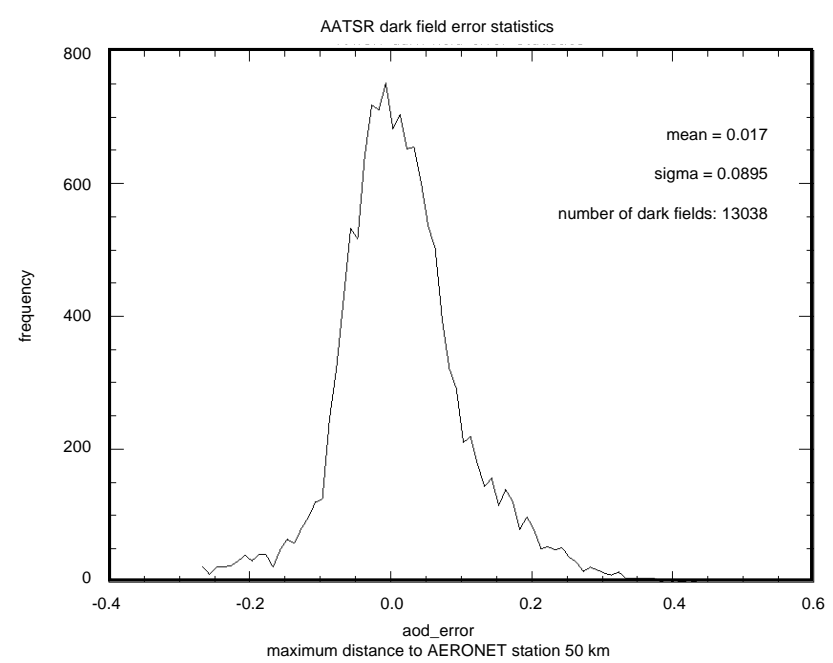

Fig. 4. Error histogram of the retrieved aerosol optical depth for real dark field pixels of ENVISAT AATSR in summer 2005 against coincident AERONET measurements in the vicinity of up to $50 \mathrm{~km}$.

of the distance between two locations considered. Available AERONET stations for three regions (Europe, USA and Middle East) were used to show this spatial de-correlation with increasing distance between two station measurements at the same time. For large distances, where no spatial correlation is expected the interpretation is difficult (possibly indicating a similarity of aerosol regimes between far off regions). However, for small distances this analysis shows the dependence of the spatial variability on region and allows to characterize the noise in a SCIAMACHY pixel and thus also against an AERONET observation which is due to atmospheric variability and not due to retrieval inaccuracies.

In Fig. 5 the result of such a variogram analysis is shown, where the RMSE of AOD at $550 \mathrm{~nm}$ is plotted as a function of the distance between the ground stations involved. Here all available AERONET ground stations in Europe (squares), the USA (triangles) and the Middle East region including Saudi Arabia (crosses) for 2003 to 2005 are included, allowing only high quality level-2 ground data for the analysis. All measurements within $\pm 30 \mathrm{~min}$ are considered for each RMSE value and each pair of ground stations, which are then grouped into bins of $50 \mathrm{~km}$ for legibility purposes.

It has to be pointed out that due to the regional distribution of the AERONET stations the database for the first bin values, at a distance of 0 to $50 \mathrm{~km}$, is very small. For all regions considered the "natural variability offset" of the curve, i.e. the variability of AOD within a very small region, is at least 0.05 . This value of atmospheric noise should always be kept in mind, as the optimal accuracy which can be reached when comparing ground to satellite measurements. 
Table 3. Summary of validation results for SYNAER/ENVISAT version 2.0 and version 1.0 versus AERONET sun photometer measurements.

\begin{tabular}{c|crc|crc}
\hline & \multicolumn{2}{|c|}{ SYNAER/ENVISAT version 2.0 } & \multicolumn{2}{c}{ SYNAER/ENVISAT version 1.0 } \\
\hline $\begin{array}{c}\text { Wavelength } \\
{[\mathrm{nm}]}\end{array}$ & pixel number & bias & $\begin{array}{c}\text { standard } \\
\text { deviation }\end{array}$ & pixel number & bias & $\begin{array}{c}\text { standard } \\
\text { deviation }\end{array}$ \\
\hline 440 & & -0.01 & 0.13 & & -0.02 & 0.15 \\
550 & 39 & 0.00 & 0.10 & 43 & 0.03 & 0.18 \\
670 & & 0.02 & 0.09 & & 0.03 & 0.14 \\
\hline
\end{tabular}

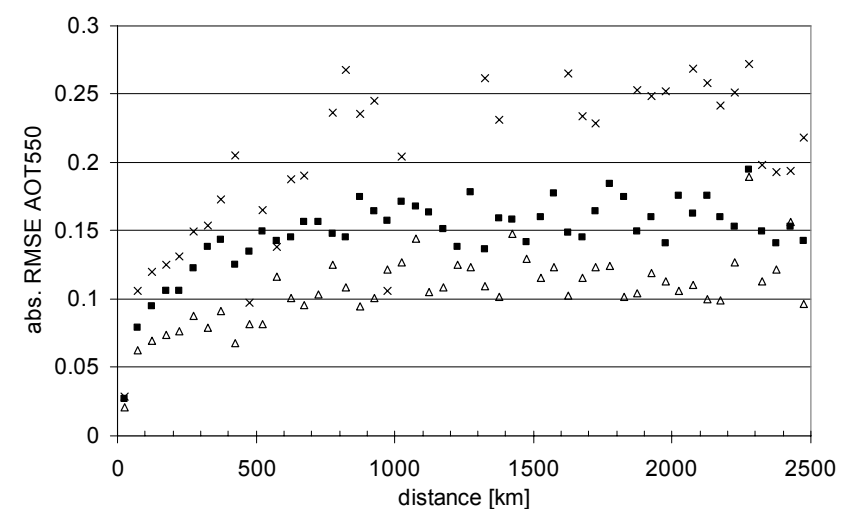

Fig. 5. Variogram of AOD550 for Europe (squares), the USA (triangles) and the Middle East Region (crosses); based on AERONET ground measurements for the years 2003-2005.

For larger distances the average variability generally increases with rising distance between the locations of ground measurements. However, there are differences for the various regions analyzed: the European stations reach an accuracy of 0.1 at approximately $200 \mathrm{~km}$ distance between two ground measurement stations, whereas the US locations can be spaced apart as far as $500 \mathrm{~km}$ to reach the same natural variability. In the Middle East this distance accounts to approximately $100 \mathrm{~km}$ only, signalizing a rather small representativeness of AOD ground measurements. This means that depending on the geographic location a different natural variability of aerosol measurements has to be taken into account when determining the accuracy limits of satellite based AOD retrieval.

The estimated order of magnitude value of 0.05 to 0.1 for this limiting lower RMSE (depending on region) shows that it is relevant when judging the AERONET validation of the SYNAER method.

4.1.2 Inter-comparison to multi-spectral ground-based measurements

Table 3 summarizes the results of the inter-comparison of SYNAER/ENVISAT version 2.0 data with AERONET sun photometer measurements and also includes respective

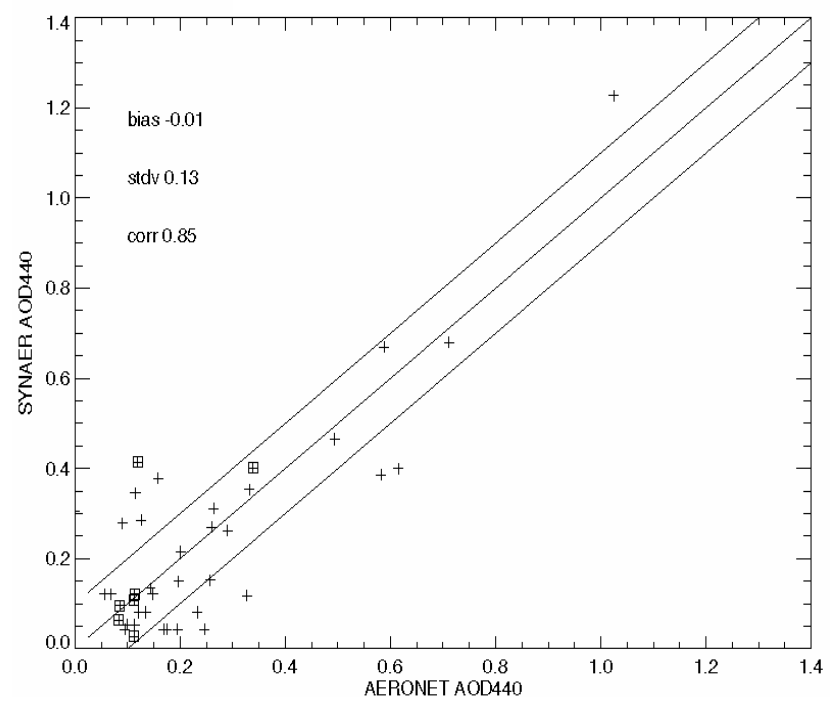

Fig. 6a. Scatter plot of SYNAER versus AERONET aerosol optical depth at $440 \mathrm{~nm}$. It should be noted that the synergetic exploitation of AATSR+SCIAMACHY is applied to the large $\left(60 \times 30 \mathrm{~km}^{2}\right)$ spectrometer pixels. Land pixels are denoted as "+", whereas coastal and ocean pixels are denoted as " $\square$ ".

inter-comparison results for SYNAER version 1.0 applied to ENVISAT data. First inter-comparisons of the new SYNAER/ENVISAT version 2.0 results to ground based sun-photometer measurements of the spectral aerosol optical depth from NASA's Aerosol Robotic Network (AERONET) at 39 locations with moderately dark surface albedo (below 0.20 at $670 \mathrm{~nm}$ ) and a fit error better than 0.01 (which is equivalent to a few percent noise in the spectra) show a good agreement with correlations above 0.80 , bias values less than 0.02 and standard deviations of $0.10(0.13,0.09)$ at $550(440$, 670) $\mathrm{nm}$ as shown in Fig. 6. The comparison to a similar analysis for SYNAER version 1.0 based on 43 locations of the same test orbits (few pixels with un-exceptional validation results do not occur in the version 2.0 dataset due to the stricter dark field surface reflectance threshold) with dark surface albedo below 0.15 at $670 \mathrm{~nm}$ and a fit error better than 0.01 shows a clear improvement of the standard deviations, which were $0.18(0.15,0.14)$ at $550(440,670) \mathrm{nm}$ 


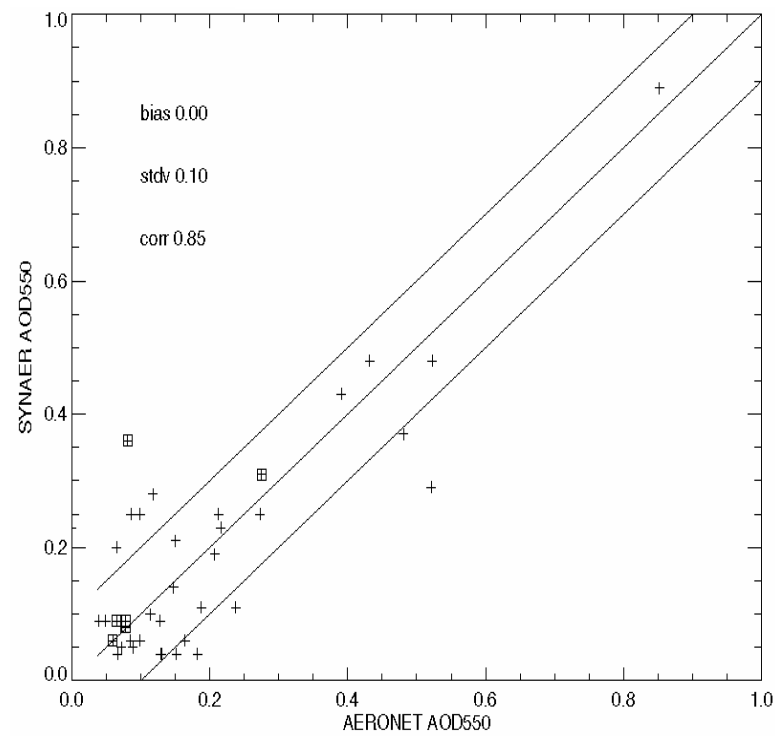

Fig. 6b. Scatter plot of SYNAER versus AERONET aerosol optical depth at $550 \mathrm{~nm}$. It should be noted that the synergetic exploitation of AATSR+SCIAMACHY is applied to the large $\left(60 \times 30 \mathrm{~km}^{2}\right)$ spectrometer pixels. Land pixels are denoted as "+", whereas coastal and ocean pixels are denoted as " $\square$ ".

for SYNAER version 1.0 (even with a stricter limit for surface reflectances of the spectrometer pixels) and a small improvement of the bias values. The good agreement of the SYNAER version 2.0 results with AERONET observations throughout the visible spectral range and the monotonic decrease from the blue to the red in parallel with decreasing ADO values indicates to a correct assessment of the amount and type (namely the spectral dependence of extinction) of aerosol, whereas in version 1.0 the non-monotonic decrease indicated partly erroneous aerosol type retrieval.

For the SYNAER pixel size and the SYNAER aerosol model which is based on external mixing of basic components (with bi- or tri-modal size distributions), an intercomparison of Angstrom coefficient data versus AERONET Angstrom coefficients is not sensible and therefore not conducted.

Through error propagation of the natural variability of at least 0.05 (coincident with the SYNAER pixel size of $60 \times 30 \mathrm{~km}^{2}$ ) from the variogram analysis of Fig. 5 a standard deviation for the SYNAER retrieval only of 0.08 at $550 \mathrm{~nm}$ can be deduced. This ground-based validation comprised data from Europe and Africa in several climate zones distributed over 3 months in the summer season of 2005 and includes pixels with limited representativeness for their surrounding area. A similar case study validation with 15 data pairs of AERONET and the predecessor satellite instruments ATSR-2/GOME onboard ERS-2 showed a similar agreement (Holzer-Popp et al., 2002b). Furthermore, a comparison of monthly mean results from SYNAER and other satellite

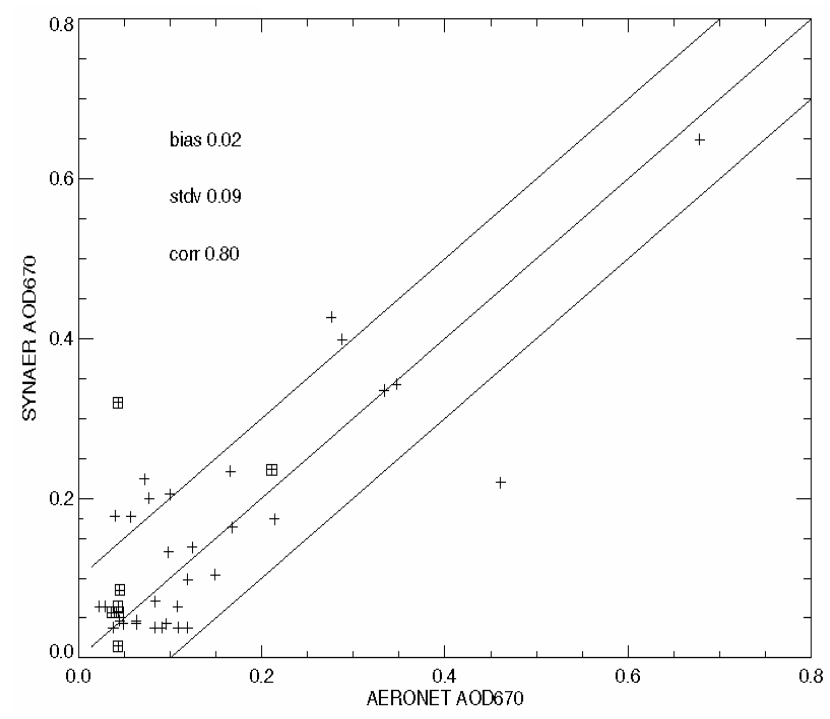

Fig. 6c. Scatter plot of SYNAER versus AERONET aerosol optical depth at $670 \mathrm{~nm}$. It should be noted that the synergetic exploitation of AATSR+SCIAMACHY is applied to the large $\left(60 \times 30 \mathrm{~km}^{2}\right)$ spectrometer pixels. Land pixels are denoted as "+", whereas coastal and ocean pixels are denoted as " $\square$ ".

aerosol retrievals as well as AERONET stations over ocean (Myhre et al., 2005) showed a qualitative agreement with the other datasets for a number of cases.

\subsection{First aerosol composition results}

\subsubsection{Analysis of aerosol composition information content} and its limitations

Using top-of-the-atmosphere nadir reflectances of two linearly independent bands of the radiometer $(1.6 \mu \mathrm{m}$ and $670 \mathrm{~nm}$ ), two independent pieces of information can be retrieved (aerosol optical depth and surface reflectance), but the aerosol mixture must be assumed. The additional use of 10 selected wavelengths between 415 and $670 \mathrm{~nm}$ from the spectrometer allows then for the discrimination between different aerosol mixtures. An analysis was made to establish theoretically the additional information content and the limitations of using the spectrometer instrument (step 2 in the retrieval) which enables the choice of the most plausible aerosol mixture. The same set of 9 basic components as in the retrieval (see Sect. 3.2) was used to define the same set of 40 mixtures. These were used to repeat the second retrieval step with simulated SCIAMACHY spectra obtained from radiative transfer calculations applying an extended successive orders of scattering algorithm as detailed in Holzer-Popp et al. (2002a) and as used in all SYNAER retrieval steps. The SYNAER retrieval step 2, itself, is based on the choice of one pre-defined aerosol mixture from the set of 40 mixtures with the help of a least square method. 


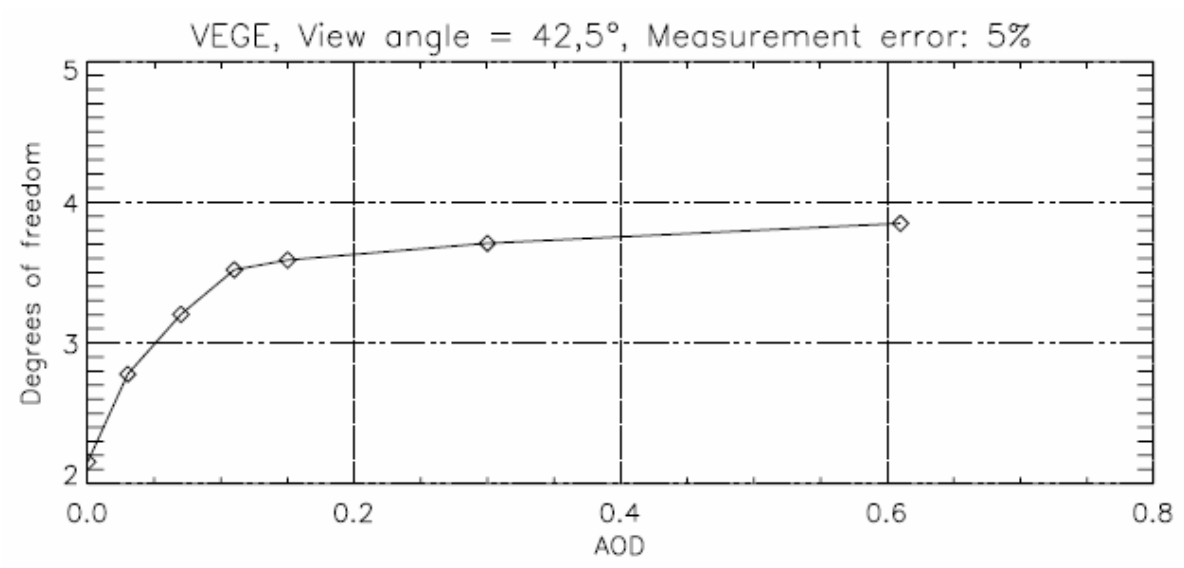

Fig. 7. Degrees of freedom as function of aerosol optical depth for solar zenith angle $42.5^{\circ}$ and surface type "vegetation".

Information theory after Rodgers (2000) was applied in an uncommon way, namely not to optimize the retrieval using an optimal estimation technique, but to independently assess the information content of the existing retrieval method. As the attention of this analysis is on capabilities and limitations to estimate aerosol composition, the percentage contributions of the 9 basic components in the 40 pre-defined aerosol mixtures are taken as the state vector in order to exactly repeat the second retrieval step. The measurement vector for the SYNAER retrieval consists of the simulated topof-atmosphere reflectances at 10 wavelengths for the 40 predefined aerosol mixtures and for one pre-defined surface type (as this is selected based on the results of step 1 in the retrieval). This setup is just another way of defining the state vector, which indirectly contains the micro-physical aerosol characteristics through the extended OPAC database. The entire setup of the theoretical analysis is mad to ensure full compatibility with the second retrieval step of SYNAER.

In this analysis of the second retrieval step, aerosol optical depth, surface reflectance and surface type for each pixel are assumed as known based on the results of the first retrieval step. The a priori error covariance matrix $S_{a}$ does only contain variables with equal normalization, namely the fraction of each aerosol component ranging from $0-100 \%$. The a priori error covariance matrix $S_{a}$ has a non-diagonal structure with explicitly calculated covariance values between percent contributions for the 40 aerosol mixtures from Table 2 describing the similarity between two distinct aerosol mixtures.

The measurement error covariance matrix $S_{\varepsilon}$ has a diagonal form assuming that spectral bands, which are tens of nanometers or hundreds of spectral pixels apart, are linearly independent, with diagonal elements $\sigma_{\varepsilon}^{2}=\left(0.05 R_{\lambda}\right)^{2}$. This represents a relative error of $5 \%$ of the reflectance values $R_{\lambda}$ at wavelength $\lambda$, while the instrument calibration error is around 1\% (Kokhanovsky et al., 2007). With this comparatively large error, the total inaccuracy of the simulated top-of-atmosphere reflectances $R_{\lambda}$ due to errors of $\mathrm{AOD}$ and surface reflectance inherited from step 1 of the retrieval are taken into account. In SYNAER self-consistency of top-of-atmosphere reflectance, AOD and surface reflectance between both retrieval steps is assured by using the same radiative transfer model and aerosol model. With the relative definition of the measurement noise a realistic estimation of the absolute noise levels is assured, which increases for brighter surfaces (with larger surface reflectance and subsequently larger top-of-atmosphere reflectances) and for shorter wavelengths (due to the farer range of aerosol extinction spectral extrapolation from the $670 \mathrm{~nm}$ retrieval wavelength).

With the methodology after Rodgers (2000) the information content is then condensed into one scalar quantity, the Degrees of Freedom for Signal (DFS). DFS can be interpreted as the number of independent linear combinations of the state vector that can be retrieved from the measurements. To quantify the information content and the limitations of the SYNAER second step for aerosol composition, DFS is plotted as function of major determining parameters. DFS as a function of AOD (for surface type "vegetation" and solar elevation of $42.5^{\circ}$ ) is shown in Fig. 7. With growing AOD, the growth of DFS values is relatively fast. This means that the SYNAER aerosol composition retrieval shows meaningful results also for small values of AOD. Already at $\mathrm{AOD}=0.1$ the curve in Fig. 7 has values around 3.5 and then approaches the saturation at about DSF=4. The offset value of DFS of 2 at $\mathrm{AOD}=0$ (i.e. no aerosol content and thus no aerosol signal) is supposed to correspond to the 2 pieces of information (surface brightness and AOD, which are provided from the first SYNAER step).

DFS also depends on other parameters such as sun elevation angle and surface type. Figure 8 describes the combined DFS dependence on sun elevation angle and AOD. The nonmonotone growth of DFS with sun elevation angle is supposed to be due to the combination of the various phase functions of the basic aerosol components. It can be seen that for 
high solar elevation DFS values reach higher than 5, whereas for solar elevation below $15^{\circ}$ DSF values are below 3.5. The results of the SYNAER retrieval are obviously also dependent on the surface type over which the retrieval is made (Fig. 9). An analysis was made for six different surface types: "vegetation", "snow", "forest", "water", "soil" and, as a special case, for "no albedo" type, which corresponds to a numerical model of absolutely black surface. Obviously, the retrieval does not work properly over very bright surfaces, such as snow or desert with DFS of approximately 2 , i.e. no additional information content for the aerosol mixture. The maximum values of DFS are over vegetation and water pixels which corresponds well with the choice of surface type for the dark field method. But also for sparsely vegetated surfaces (see the "soil" example) the information content for the aerosol mixture is weaker but still remains above 3.5.

To assess the sensitivity of the information content analysis the measurement noise level was increased by $1 \%$ and the analysis showed only a decrease of the DSF values on the order of 0.15 ; even for a doubled measurement noise of $10 \%$ the DSF values decreased only by 0.5 . This emphasizes the stability of the information content analysis and its underlying error assumption.

In summary, this analysis shows that DFS (after eliminating the offset of 2 due to surface brightness and AOD) exhibits a variation from 0 . to more than 3 . depending on AOD, solar elevation and surface type. These values correspond only to the determination of the aerosol mixture in the second SYANER step. It is thus theoretically proven that SYNAER can determine more than 2 independent aerosol properties in addition to AOD and surface brightness by exploiting the synergy of the two instruments. Also this analysis provides a deeper insight into favourable conditions and limitations of the aerosol composition retrieval with SYNAER (surface, sun elevation, AOD). It was found that for $\mathrm{AOD}<0.1$ the information content with regard to the aerosol mixture decreases rapidly and therefore these results can not be used to interpret atmospheric aerosol composition. On the other hand all solar elevation angles for which SYNAER step 1 is applied (solar elevation larger than $15^{\circ}$ ) and all surface types where dark fields are found for step 1 (i.e. all except desert and snow) can be used in the second SYNAER retrieval step.

\subsubsection{Monthly and seasonal datasets}

Figures 10 to 12 show examples of the complete coverage of the currently available SYNAER ENVISAT dataset. Figures 10 and 11 were obtained with SYNAER version 2.0, whereas Fig. 12 shows an example inter-comparison with version 1.0. In this analysis results of the theoretical assessment of the information content in Sect. 4.2.1 (Figs. 79) where applied by introducing a synthetic component "unknown", where the complete AOD of all pixels with $\mathrm{AOD}<0.1$ where included in. The dataset in Fig. 10 gives the 4-month average values for the period July-October 2003

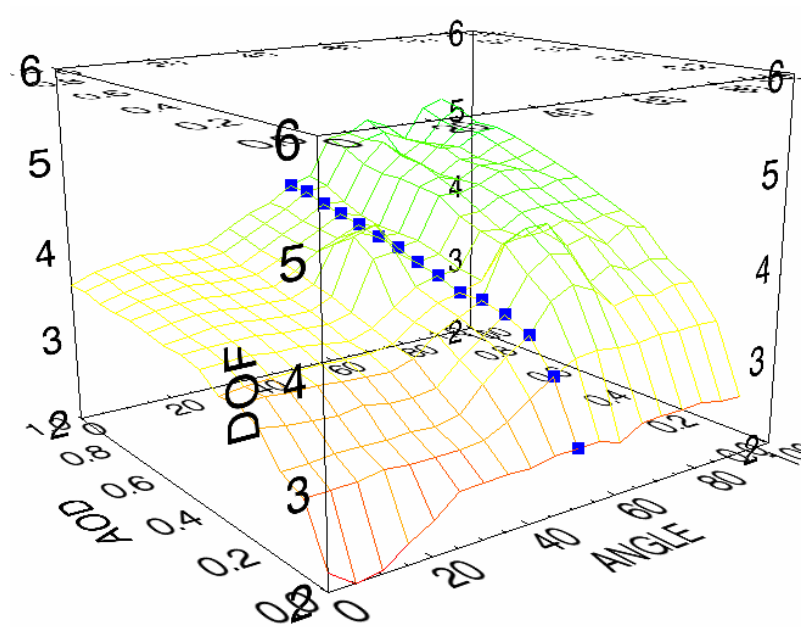

Fig. 8. Degrees of freedom as function of aerosol optical depth and solar elevation angle for surface type "vegetation". The blue dots indicate the line of Fig. 7.

on a $2^{\circ} \times 2^{\circ}$ grid. In this time period a reasonable coverage in this grid is achieved with up to 200 pixels from up to 10 different overpass days within this period (as opposed to the earlier ERS-2 coverage, which needed one year of data for a similar pixel number on a $5 \times 5^{\circ}$ grid). The nine basic components of Table 1 have been integrated into four major physical aerosol species: water-soluble, soot (biomass burning and diesel), sea salt (both size modes), and mineral dust (transported and insoluble with low and high hematite content). Some values towards the edges of the covered region with only few pixels and possibly only covering 1 or 2 overpass days (e.g. in Southern America) must still be used with great caution, as there the exploited pixel numbers decrease significantly, so that a single episode can determine the "average" value.

Although validation of this aerosol composition dataset is solely based on the indirect validation through spectral AOD, in the total aerosol optical depth and the aerosol component maps distinct features can be seen which are very plausible. It should be noted that in relation to the occurring AOD values different color bars have been used for total AOD and the various component AODs to clearly show the major features. In the figures regional boxes have been drawn and annotated with small letters from "a" to " $n$ " to be used in the description for reference (red: soot; orange: mineral dust; blue: sea salt component). The major features in total AOD are the tropical biomass burning regions in Africa (region $\mathrm{d}$ and $\mathrm{k}$ ), the sub-tropical desert regions (Sahara and Arabia region $\mathrm{f}, \mathrm{Namib} /$ Kalahari - region $\mathrm{g}$ ) and the biomass burning plume over the Atlantic Ocean (regions a and b). Furthermore, a weaker signal is visible over the Mediterranean (c) and (due to limited sampling) in the South American biomass burning region (e) as well as in the Southern Atlantic Ocean (h). These features are also to some extent vis- 


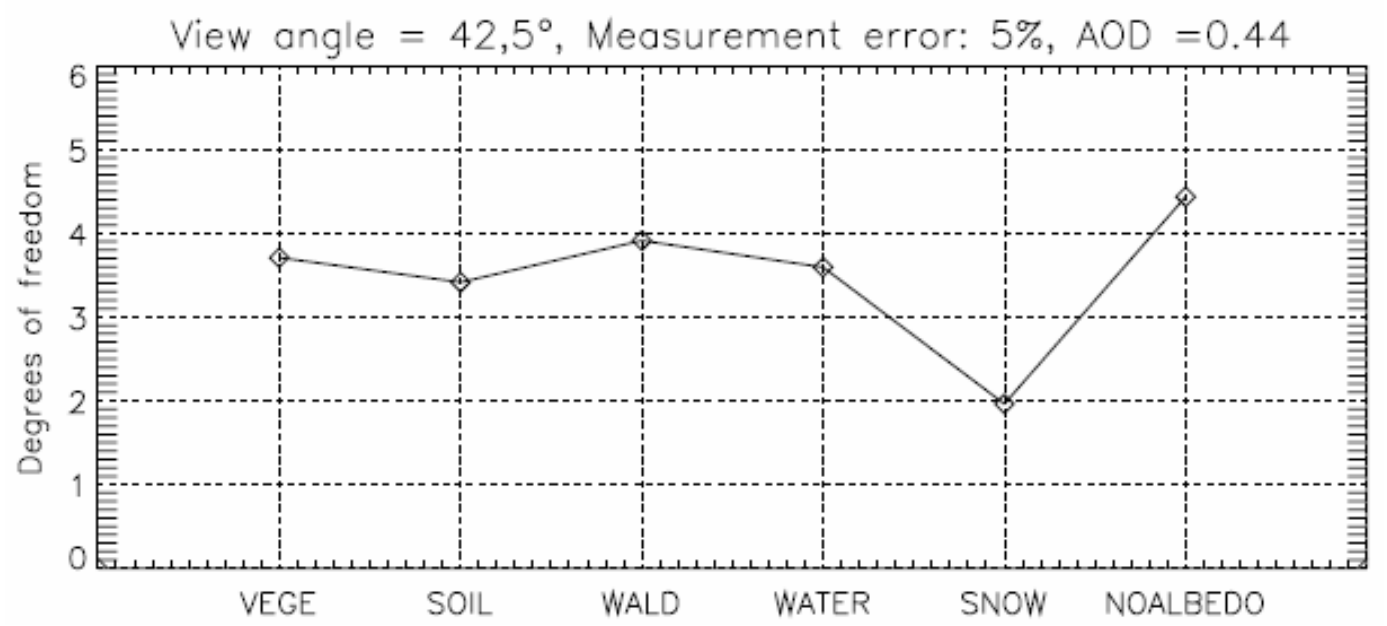

Fig. 9. Degree of freedom for $A O D=0.35$ and solar zenith angle $42.5^{\circ}$ for different surface types.

ible in the water-soluble component, since this component contributes to all pre-defined aerosol mixtures in SYNAER (see Table 2). However, AOD values for the water-soluble component in the regions with mineral, soot and sea salt components are clearly reduced as other components add to the total AOD. The synthetic "unknown" component shows weak features (lowest at peak AOD regions, lower over ocean than over land) with values below 0.1 (as by its definition) and most likely includes part of the missed South American biomass burning and maritime sea salt background. The soot component has its peaks in the biomass burning regions and over the Atlantic Ocean. However, South America is mostly missed in the soot component, but has some higher values in the water-soluble component (which can also be associated with organic weakly absorbing small biomass burning secondary particles). Mineral components concentrate around the desert areas, but no retrieval is possible inside the Sahara due to the bright surface. The sea salt component is only prevailing in few boxes close to the South Atlantic Ocean's "roaring forties", whereas elsewhere the lower AOD values over the clean oceans are mostly put into the "unknown component" leaving no background discernable in the sea salt component. As Fig. 12 shows version 2.0 means a significant improvement in avoiding a miss-classification of aerosol loading as sea salt inside Southern Africa (region n).

The seasonal behavior visible in the SYNAER data is indicated in Fig. 11 (with a color bar for the soot AOD values ranging up to 0.2) for the soot component in months January, April, August and October, though with very small pixel numbers (maximum 50 pixels with 2 overpass times) contributing to each grid cell. Here, following major features can be seen: From January to October the tropical biomass burning over Africa moves South-East (from the Sahel region $\mathrm{k}$ to Southern Africa region d), and to a lesser extent also its plume over the Atlantic Ocean moves southwards (from re- gion a to b). Over large parts of Europe, no data are available in January (due to low sun, high cloudiness and snow cover). Highest Northern European soot concentrations (region m) are detected, when observations are becoming available still in the heating season (April). Additionally, wildfires in August (hot summer 2003 in Europe) contribute to clearly elevated soot over the Iberian peninsula (Western edge of region c) and weaker in the entire Mediterranean region (c). The elevated soot values over the tropical Atlantic Ocean (a) in August and October indicate to outflow from South America, but soot over land is only detected for few boxes in $\mathrm{Au}-$ gust over the Amazonian region. Further biomass burning in South America is probably interpreted as water-soluble or missed due to limited sampling (possibly still erroneous cloud detection over very dense smoke). Most of these features are not as clearly visible in the total aerosol optical depth which is the sum of all aerosol components, whereas the water-soluble component shows correlated features as it is also partly linked to biomass burning emissions (and organic or water-coated carbon particles partly have optical features similar to the WASO component).

In Fig. 12 the 4-monthly maps of the four major components derived with SYNAER/ENVISAT version 1.0 are shown for comparison with results of version 2.0. The watersoluble component shows similar features but with generally higher values for version 1.0 and some regional differences associated with changes in the other components. Sea salt had a major miss-interpretation inland Southern Africa in version 1.0, which does no longer occur, whereas the higher Southern latitudes Atlantic Ocean peak is new in version 2.0. The mineral dust values around the Sahara are slightly increased in the new version, whereas the regional extent of mineral dust in Southern Africa has been reduced. For the soot component version 2.0 shows higher values over the Mediterranean and the Atlantic Ocean, but a mostly missed 

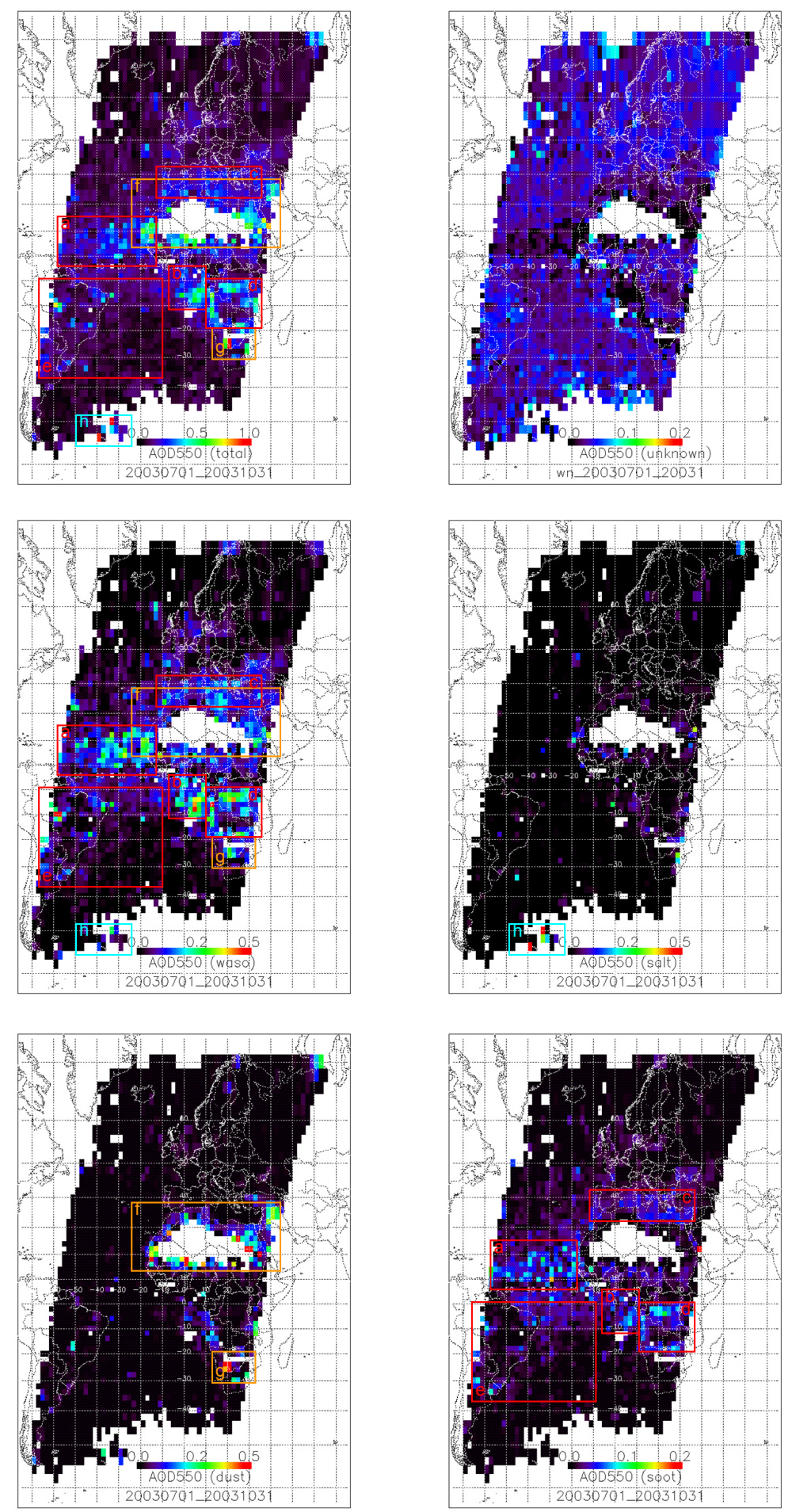

Fig. 10. Examples of a 4-monthly average map based on SYNAER version 2.0 data of July-October 2003 on a $2^{\circ} \times 2^{\circ}$ grid: upper line from left to right: total AOD at $550 \mathrm{~nm}$, "unknown" component $(\mathrm{AOD}<0.1)$, central line from left to right: AOD at $550 \mathrm{~nm}$ of water-soluble aerosols and of sea salt aerosols; lower line from left to right: component AOD at $550 \mathrm{~nm}$ of mineral dust and soot aerosols. Note the different color bars ranging from 0.0 to 1.0 for total AOD, 0.0 to 0.5 for water-soluble, sea salt and mineral dust AOD, and from 0.0 to 0.2 for "unknown", and soot AOD. 

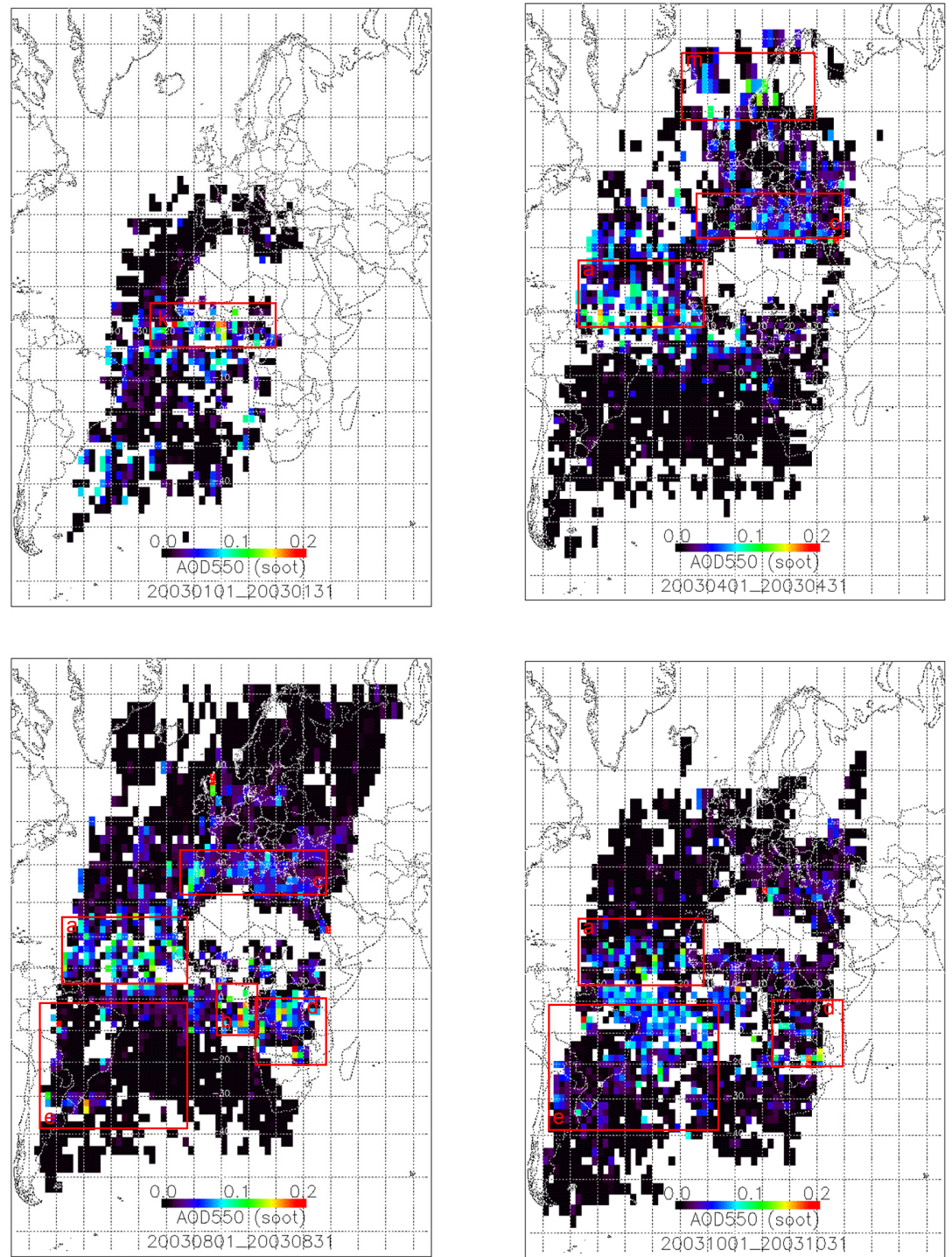

Fig. 11. Seasonal variation of soot in SYNAER version 2.0 data: Monthly average AOD on a $2^{\circ} \times 2^{\circ}$ grid of the soot component for the months January, April, August, and October 2003 are shown from top left to bottom right.

contribution over Southern America (which had partly been detected but also outside the Amazonian forest fire region in version 1.0) and regional reduction over Southern Africa.

\section{Discussion and outlook}

The SYNAER method provides a retrieval, which exploits the optical measurements made from two sensors in one retrieval algorithm. One significant drawback from this synergetic application is the limited spatial resolution of $60 \times 30 \mathrm{~km}^{2}$ and the weak temporal repetition frequency of 12 days at the equator in cloud-free conditions. On the other hand the gain lies in the joint exploitation of 10 spectrometer and 3 radiometer spectral channels. Consecutively, the in- formation content in this retrieval enables under favourable conditions the independent retrieval of not only the aerosol loading (aerosol optical depth), but also an estimation of its composition.

In this paper several improvements of the SYNAER method are described and their application with the new sensor pair SCIAMACHY and AATSR is demonstrated and validated. Given the pixel size the retrieval accuracy of around 0.1 at $550 \mathrm{~nm}$ (or 0.08 after atmospheric noise deduction) against AERONET surface-based sun photometer measurements is satisfactory. Furthermore, the monotone decrease of the standard deviation with increasing wavelength (from 440 to $670 \mathrm{~nm}$ ) is proportional with the decreasing average AOD and this indicates to a plausible retrieval of the aerosol type. 

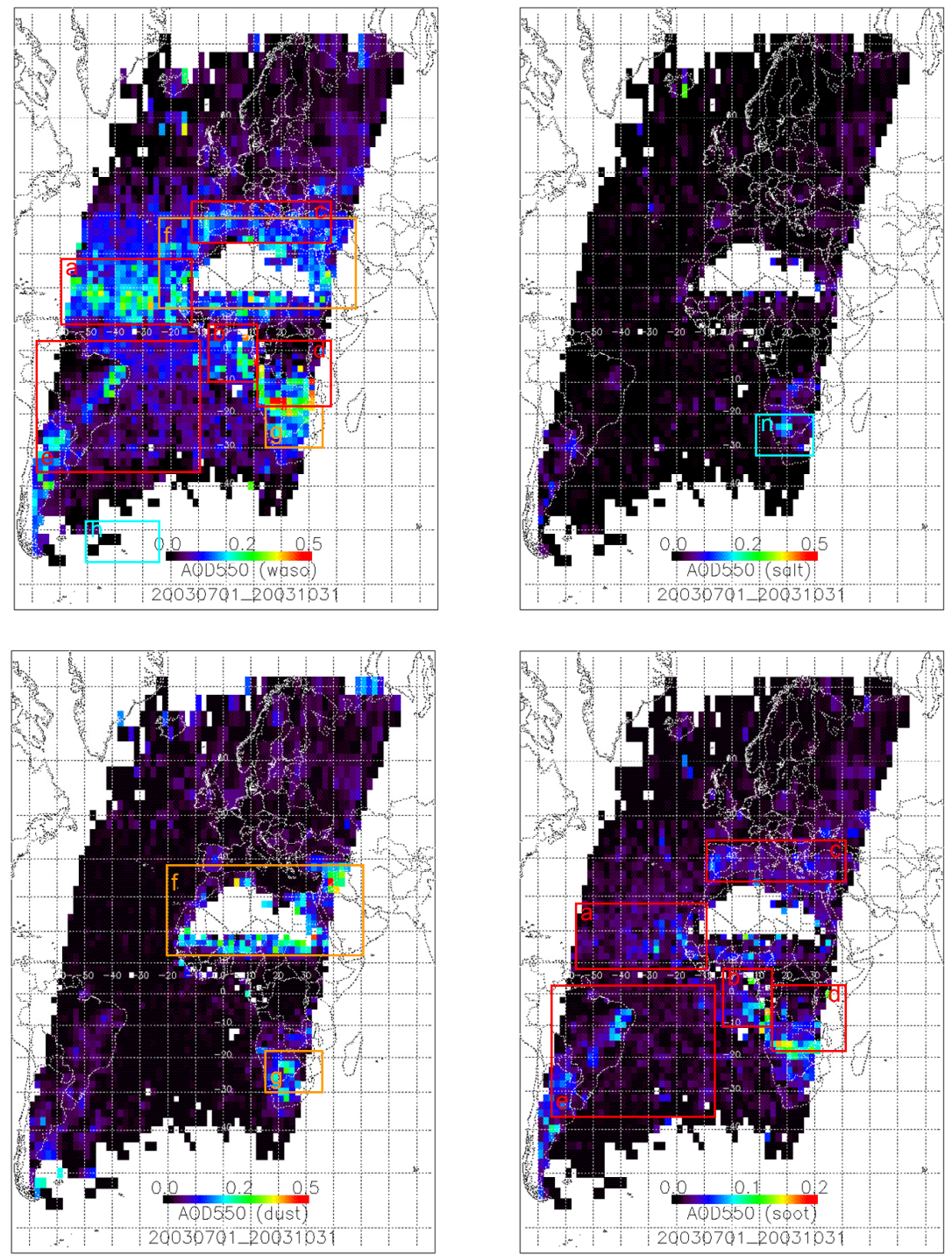

Fig. 12. Inter-comparison of SYNAER version 1.0 and 2.0: for the 4-monthly average as shown in Fig. 10 (version 2.0) the respective results for water-soluble, sea salt mineral dust and soot components (from top left to bottom right) obtained with version 1.0 are shown.

As the validation of the retrieved aerosol composition is extremely difficult due to a lack of equivalent groundbased data, only an indirect validation approach through multi-spectral AOD measurements is used so far. Validation of satellite derived information with this large pixel size and low spatial-temporal coverage is further impeded due to atmospheric noise and the limited number of ground-based stations. It is also important to understand, that this type of satellite retrieval depends critically on the aerosol model chosen and its limitations or its complexity. In the end, the retrieval of aerosol composition must therefore be considered as a way of interpretation of the optical measurements. But, it is the conviction of the authors that the plausible results shown in this paper encourage further work in this direction.
The validation against AERONET stations includes as many pixels as possible and particularly cases with special features such as high AOD or different aerosol regimes. Thus, also several cases where the representativeness of the ground-based station for the SYNAER pixel is weak or could not be determined are included. Examples are Fontainbleau (at the edge of the mega-city Paris), Ispra (at the edge of an Alpine valley), Erdemli (at the coast with high mountains behind). In all these cases the local AOD regime at the station differs significantly from the regional AOD. One extreme case at Teneriffe island was excluded by the ambiguity test of SYNAER. Here 2 stations (Izana at $2367 \mathrm{~m}$ a.s.l. with an AOD550 of 0.39 and Santa Cruz at sea level with an AOD550 of 0.71) fall into 1 SYNAER pixel (AOD550=0.94) thus highlighting the possible variability and dependence on 
station elevation inside a SYNAER pixel for an extreme case of a desert dust outbreak and the subsequent limitation for the AERONET inter-comparison. Future research is intended to better characterize the representativeness of a respective AERONET station for the SYNAER pixel size. Taking into account that also difficult validation locations are included in this analysis, its results are even more satisfactory.

A theoretical analysis of the information content with regard to aerosol composition in the second step of the methodology was conducted to understand the capabilities of using an additional instrument and to assess the limitations of this approach. This analysis showed that up to 5 degrees of freedom ( 1 for surface reflectance, 1 for AOD and up to 3 for the aerosol mixture) can be retrieved and thus supports the conclusion, that an estimation of the aerosol composition is becoming feasible under favourable conditions with this method. Under typical conditions over vegetated surfaces 2 degrees of freedom are available for information on the aerosol mixture. As one major result of the theoretical analysis, the dependence of the retrievable information content on aerosol optical depth, solar elevation and surface type could be established. This result was used to define a synthetic component "unknown", where all retrieved pixels with low $\mathrm{AOD}<0.1$ where included. Furthermore it was confirmed, that all surface types and solar elevations exploited in the first retrieval step can be used in the second retrieval step.

As two independent parameters (e.g. spectral extinction gradient and absorption) are needed to differentiate monomodal aerosol distributions, this would be sufficient to characterize the pure aerosol types. At least one more degree of freedom is needed for bi-modal aerosol distributions, which is then only feasible for the best possible conditions. Further analysis is required to interpret the information content with regard to these different parameters. For example the apparent absorption sensitivity in the method (being able to differentiate water-soluble and soot components) may also be provided by the integrating of different scales of the 2 instruments $(1 \mathrm{~km}$ and $60 / 30 \mathrm{~km})$ and thus by averaging dark and bright pixels, which is sensitive to the non-linearity in radiative transport. As the two steps of the retrieval method are applied to two different sensors with different pixel size, a comprehensive information content analysis for the whole methodology (including the cloud detection pre-processor) or of the impact of the improvements described in Sect. 3 would be beyond this paper and further research is planned for this task.

Due to the vegetation-dependence (as similarly treated for MODIS Collection 5) of the correlation of the $1.6 \mu \mathrm{m}$ with the $670 \mathrm{~nm}$ channel a large effort (described in Sect. 3.3.) was made to improve the accuracy and global applicability of this dark field approach; the goal was never to treat bright surfaces with this step, which would require a completely different approach (e.g. using surface reflectance databases for dry regions). In step 2 of the retrieval a significant extension in application to brighter surface reflectances was proven during the validation ( $R_{670}$ up to 0.20$)$ against version 1.0 (where the appropriate limit was 0.15 ). In conclusion the method can also be used over moderately dark surfaces if there are at least few dark spots $\left(R_{670}<0.08\right)$ suitable for the $1 \mathrm{~km}^{2}$ AOD retrieval within or nearby the larger spectrometer pixel.

The spatial patterns visible in the first composition datasets (version 2.0) over Europe, Africa, the Atlantic Ocean and parts of South America are mostly in agreement with the known seasonal and regional features. This demonstration has only become possible through the transfer from ERS-2 to ENVISAT, which meant a significant step in temporal sampling, since ERS-2 provided a suitable pixel size of $80 \times 40 \mathrm{~km}^{2}$ only for 3 days in each month. One specific feature, which has not shown up in MODIS Collection 5 AOD or coarse mode maps but was detected in MODIS deep blue results (Hsu et al., 2004) is the mineral dust AOD over the Namib/Kalahari region. This feature has been reduced in its regional extent in version 2.0, but still remains. This region is shown in dust mobilization models as source of mineral dust which are - different from the Saharan region - normally not transported away from their origin due to the prevailing wind regime in this region. A dust plume over the Atlantic Ocean in the mineral dust component map is not to be expected in this dataset due to the season (normally desert dust outbreaks occur mostly before and after the 4-month period treated in this paper).

Clearly the impact of the improvements in the methodology can be seen in the validation against AERONET sun photometer measurements (as summarized in Table 3 ) and in averaged datasets. Larger soot AOD values over the sub tropical Northern Atlantic Ocean and lower dust AOD values over the Sahel are most likely due to the improved cloud filtering in the dust regime, but still a possible miss-interpretation of heavy smoke over the Amazonian region as clouds needs to be assessed. The better distinction between the coarse mode particles (dust, salt) over land and the higher soot AOD over the Mediterranean are probably due to the updated aerosol model. The extended dark field method leads to reduced soot and dust AOD values in Southern African semi-arid regions.

As all satellite retrieval algorithms for aerosols SYNAER is limited by a mathematically ill-posed system and by computing resources, which makes several assumptions and simplifications necessary. These are in addition to the limited sampling the limitation to spherical particles (Mie scattering), the dependence on the pre-defined aerosol mixtures, the decreasing information content with brighter surfaces, and the general optical remote sensing limitations for low sun and high cloud fraction. The limitation to spherical particle shape could have been overcome by using an approximated effective phase function for non-spherical particles, but this would have increased further the aerosol model complexity, where no specific sensitivity to particle shape is provided by this nadir-only un-polarized retrieval method. One additional element in the application of SYNAER results for the deriva- 
tion of monthly and seasonal datasets is the utilization of the theoretical limitations to each pixel's geometric and surface condition.

The validation of the derived aerosol composition requires further work. One planned approach will use EMEP mass speciation fractions to determine the presence of soot (elemental and organic carbon), mineral dust and sea salt and inter-compare with the SYNAER composition. Other possibilities lie in the inter-comparison to model and other satellite datasets (e.g. MODIS fine/coarse mode, future MISR aerosol composition product).

The application potential of SYNAER ranges from data assimilation into atmospheric chemistry transport models for climate research and air quality monitoring and forecasting to service applications such as accurate calculation and forecast (through assimilation into a forecast model) of solar irradiance for solar energy applications (see for example Breitkreuz et al. 2007). Finally, the estimation of the aerosol type provides one critical information for a systematic conversion of AOD into near surface mass concentrations (PM values; e.g. Holzer-Popp and Schroedter-Homscheidt, 2004), which is the key quantity for regulatory purposes.

Due to the need for overlap of two sensors with very different scan patterns, the coverage of SYNAER/ENVISAT is still quite weak providing approximately one synergetic observation every 12 days if no clouds do occur. This leads to the need for large integration grid boxes or time periods. The potential for independent estimation of the aerosol mixture can be shown, but daily monitoring applications are only feasible by assimilation into atmospheric chemistry models. A further improved coverage (every 1-2 days globally) will be achieved with the transfer to equivalent sensors AVHRR and GOME-2 onboard the operational meteorological METOP platform. A prototype is already available, but needs further adjustments for the instrument characteristics and calibration. Finally, by integrating SYNAER results from ERS2, ENVISAT and METOP there is a perspective to achieve a long-term record of AOD and composition ranging from 1995-2020. It was always in the light of this final goal, that specific instrument characteristics such as the ATSR dual view or the SCIAMACHY mid-infrared bands or limb observations were not exploited to assure application of SYNAER to all 3 satellite datasets. However, the different pixel sizes and sampling will need thorough assessment when integrating these 3 datasets.

SYNAER/ENVISAT has been implemented for operational processing at the German Remote Sensing Data Center within the ESA GSE PROMOTE (Protocol Monitoring for the GMES Service Element; see also http://www. gse-promote.org) and delivers daily near-real time observations (within the same day) and an evolving archive of historic data. SYNAER data are stored at the World Data Center for Remote Sensing of the Atmosphere (http://wdc.dlr.de).
Acknowledgements. We are thankful to ESA for providing the satellite observations from ERS-2 and ENVISAT platforms, which are exploited with the SYNAER method through announcement of opportunity projects PAGODA-2 and SENECA as well as for funding the validation and application of SYNAER to ENVISAT as part of the ESA GMES Service Element PROMOTE (Stage 2). Furthermore we appreciate the independent validation dataset from the AERONET ground-based sun photometers provided by Brent Holben and all involved AERONET PIs.

Edited by: M. van Roozendael

\section{References}

Breitkreuz, H., Schroedter-Homscheidt, M., and Holzer-Popp, T.: A case study to prepare for the utilization of aerosol forecasts in solar energy industries, Sol. Energy, 81, 1377-1385, 2007.

Claquin, T., Schulz, M., and Balkanski, Y. J.: Modelling the mineralogy of atmospheric dust sources, J. Geophys. Res., 104(D18), 22243-22356, 1999.

Deuzé, L., Bréon, F. M., and Devaux, C.: Remote sensing of aerosols over land surfaces from POLDER-ADEOS - 1 polarized measurements, J. Geophys. Res., 106(D5), 4913-4926, 2001.

Dubovik, O., Holben, B., Eck, T. F., Smirnov, A., Kaufman, Y. J., King, M. D., Tanre, D., and Slutsker, I.: Variability of Absorption and Optical Properties of Key Aerosol Types Observed in Worldwide Locations, J. Atmos. Sci., 59, 590-608, 2002.

Dunion, J. P. and Velden, C. S.: The impact of the Saharan Air Layer on Atlantic tropical cyclone activity, Bull. Am. Meteorol. Soc., 90, 353-365, 2004.

Evan, A. T., Heidinger, A. K., and Pavalonis, M. J.: Development of a new over-water Advanced Very High Resolution Radiometer dust detection algorithm, Int. J. Remote. Sens., 27, 3903-3924, 2006.

Fan, X., Goloub, P., and Deuzé, J.-L.: Evaluation of PARASOL aerosol retrieval over North East Asia, Remote Sens. Environ., 112(3), 697-707, doi:10.1016/j.rse.2007.06.010, 2007.

Hess, M., Koepke, P. , and Schult, I.: Optical properties of aerosols and clouds: The software package OPAC, Bull. Am. Meteorol. Soc., 79(5), 831-844, 1998.

Holzer-Popp, T., Schroedter, M., and Gesell, G.: Retrieving aerosol optical depth and type in the boundary layer over land and ocean from simultaneous GOME spectrometer and ATSR-2 radiometer measurements, 1, Method description, J. Geophys. Res., 107(D21), AAC16-1-AAC16-17, 2002a.

Holzer-Popp, T., Schroedter, M., and Gesell, G.: Retrieving aerosol optical depth and type in the boundary layer over land and ocean from simultaneous GOME spectrometer and ATSR-2 radiometer measurements, 2, Case study application and validation, J. Geophys. Res., 107(D24), AAC10-1-AAC10-8, 2002b.

Holzer-Popp, T. and Schroedter-Homscheidt, M.: Satellite-based background concentration maps of different particle classes in the atmosphere, edited by: Brebbia, C. A., Air Pollution XIII, WIT Press, Southampton, 2004.

Hsu, N. C., Tsay, S.-C., King, M., and Herman, J. R.: Aerosol Properties Over Bright-Reflecting Source Regions, IEEE T. Geosci. Remote, 42(3), 557-569, 2004.

Huang, J., Minnis, P., Lin, B., Wang, T., Yi, Y., Hu, Y., SunMack, S., and Ayers, K.: Possible influences of Asian dust 
aerosols on cloud properties and radiative forcing observed from MODIS and CERES, Geophys. Res. Lett., 33, L06824, doi:10.1029/2005GL024724, 2006.

Kahn, R. A., Gaitley, B. J., Martonchik, J. V., Diner, D. J., Crean, K. A., and Holben, B.: Multiangle Imaging Spectroradiometer (MISR) global aerosol optical depth validation based on 2 years of coincident Aerosol Robotic Network (AERONET) observations, J. Geophys. Res., 110, D10S04, doi:10.1029/2004JD004706, 2005.

Kaufman, Y. J. and Fraser, R. S.: The effect of smoke particles on clouds and climate forcing, Science, 277, 1636-1639, 1997.

Kaufman, Y. F., Tanré, D., and Remer, L. A.: Operational remote sensing of tropospheric aerosol over land from EOS Moderate Resolution Imaging Spectroradiometer, J. Geophys. Res., 102, 17051-17067, 1997.

Kaufman, Y. J., Tanre, D., and Boucher, O.: A satellite view of aerosols in the climate system, Nature, 419, 215-223, 2002.

Kokhanovsky, A. A., von Hoyningen-Huene, W., and Burrows, J. P.: Atmospheric aerosol load as derived from space, Atmos. Res., 81, 176-185, 2006.

Kokhanovsky, A. A., Bramstedt, K., von Hoyningen-Huene, W., and Burrows, J. P.: The intercomparison of top-of-atmosphere reflectivity measured by MERIS and SCIAMACHY in the spectral range of 443-865 nm, IEEE Trans. Geosci. Rem. Sens. Lett., 4, 293-296, 2007.

Kriebel, K. T., Saunders, R. W., and Gesell, G.: Optical properties of clouds derived from fully cloudy AVHRR pixels, Beiträge zur Physik der Atmosphäre, 8, 723-729, 1989.

Kriebel, K. T., Gesell, G., Kästner, M., and Mannstein, H.: The cloud analysis tool APOLLO: Improvements and Validation, Int. J. Remote. Sens., 24, 2389-2408, 2003.

Levy, R. C., Remer, L. A., Mattoo, S., Vermote, E. F., and Kaufman, Y. J.: Second-generation operational algorithm: 25 Retrieval of aerosol properties over land from inversion of Moderate Resolution Imaging Spectroradiometer spectral reflectance, J. Geophys. Res., 112, D13211, doi:10.1029/2006JD007811, 2007.

Marsh, S. H., Dean, S. M., and Grainger, R. G.: An Optimal Estimation Aerosol Retrieval Scheme for ATSR-2. Atmospheric, Oceanic and Planetary Physics (AOPP) Memorandum 2004.2, University of Oxford, UK, 2004.

Moulin, C., Gordon, H. R., Banzon, V. F., and Evans, R. H.: Assessment of Saharan dust absorption in the visible from SeaWiFS imagery, J. Geophys. Res., 106(D16), 18239-18249, 2001.

Myhre, G., Stordal, F., Johnsrud, M., Diner, D. J., Geogdzhayev, I. V., Haywood, J. M., Holben, B. N., Holzer-Popp, T., Ignatov, A., Kahn, R. A., Kaufman, Y. J., Loeb, N., Martonchik, J. V., Mishchenko, M. I., Nalli, N. R., Remer, L. A., SchroedterHomscheidt, M., Tanré, D., Torres, O., and Wang, M.: Intercomparison of satellite retrieved aerosol optical depth over ocean during the period September 1997 to December 2000, Atmos. Chem. Phys., 5, 1697-1719, 2005,

http://www.atmos-chem-phys.net/5/1697/2005/.

Patterson, E. M., Gillete, D. A., and Stockton, B. H.: Complex index of refraction between 300 and $700 \mathrm{~nm}$ for Saharan aerosol, J. Geophys. Res., 82, 3153-3160, 1997.

Pohl, O.: News scan: Disease Dustup, Sci. Am., 7, 10-11, 2003.

Pope III, C. A., Burnett, R. T., Thun, M. J., Calle, E. E., Krewski, D., Ito, K., and Thurston, G. D.: Lung Cancer, Cardiopulmonary Mortality, and Long-term Exposure to Fine Particulate Air Pol- lution, Jama-J. Am. Med. Assoc., 287, 1132-1141, 2002.

Prospero, J. M., Ginoux, P., Torres, O., Nicholson, S., and Gill, T.: Environmental characterization of global sources of atmospheric soil dust identified with the NIMBUS 7 Total Ozone Mapping Spectrometer (TOMS) absorbing aerosol product, Rev. of Geophys., 41(1), 2-1-2-31, doi:10.1029/2000RG000095, 2002.

Remer, L. A., Kaufman, Y. J., Tanré, D., Mattoo, S., Chu, D. A., Martins, J. V., Li, R.-R., Ichoku, C., Levy, R. C., Kleidman, R. G., Eck, T. F., Vermote, E., and Holben, B. N.: The MODIS aerosol algorithm, products, and validation, J. Atmos. Sci., 62(4), 947-973, 2005.

Robles-Gonzalez, C., de Leeuw, G., Decae, R., KusmierczykMichulec, J., Stammes, P.: Aerosol properties over the Indian Ocean Experiment (INDOEX) campaign area retrieved from ATSR-2, J. Geophys. Res., 111, D15205, doi:10.1029/2005JD006184, 2006.

Rodgers, C. D.: Inverse methods for atmospheric sounding, Theory and Practice, World Scientific Publishing Company, London, UK, ISBN 981-02-2740-X, 2000.

Rosenfeld, D. and Lensky, I. M.: Satellite-based insights into precipitation formation processes in continental and maritime convective clouds, Bull. Am. Meteorol. Soc., 79, 2457-2476, 1998.

Saunders, R. W. and Kriebel, K. T.: An improved method for detecting clear sky and cloudy radiances from AVHRR data, Int. J. Remote Sens., 9, 123-150, 1988.

Schnaiter, M., Horwath, H., Möhler, O., Naumann, K.-H., Saathoff, H., and Schöck, O. W.: UV-VIS-NIR spectral optical properties of soot and soot-containing aerosols, J. Aerosol Sci., 34, 14211444, 2003.

Sinyuk, A., Torres, O., and Dubovik, O.: Combined use of satellite and surface observations to infer the imaginary part of refractive index of Saharan dust, Geophys. Res. Lett., 30(2), 1081, doi:10.1029/2002GL016189, 2003.

Stedman, J. R.: The predicted number of air pollution related deaths in the UK during the August 2003 heatwave, Atmos. Environ., 38, 1087-1090, 2004.

Veefkind, J. P. and de Leeuw, G.: A new algorithm to determine the spectral aerosol optical depth from satellite radiometer measurements, J. Aerosol Sci., 29(10), 1237-1248, 1998.

Veefkind J. P., de Leeuw, G., Durkee, P. A., Russell, P. B., Hobbs, P. V., and Livingston, J. M.: Aerosol optical depth retrieval using ATSR-2 data and AVHRR data during TARFOX, J. Geophys. Res., 104(D2), 2253-2260, 1999.

von Hoyningen-Huene, W., Freitag, M., and Burrows, J. B.: Retrieval of aerosol optical thickness over land surfaces from top-of-atmosphere radiance, J. Geophys. Res., 108, D94260, doi:10.1029/2001JD002018, 2003.

Wang, J., Christopher, S. A., Reid, J. S., Maring, H., Savoie, D., Holben, B. H., Livingston, J. M., Russel, P., and Yang, S. K.: GOES 8 retrieval of dust aerosol optical thickness over the Atlantic Ocean during PRIDE, J. Geophys. Res., 108, PRD11.1PRD11.15, 8595-8609, doi:10.1029/2002JD002494, 2003.

Wong, S. and Dessler, A. E.: Suppression of deep convection over the tropical North Atlantic by the Saharan Air Layer, Geophys. Res. Lett., 32, L09808, doi:10.1029/2004GL022295, 2005.

World Climate Program (WCP): A Preliminary Cloudless Standard Atmosphere for Radiation Computation, WCP-112, WMO/TD No. 24, Boulder, 1986. 